\title{
Gas hold up in bubble column at high pressure and high temperature
}

\section{Clément Leonard ${ }^{\mathrm{a}, \mathrm{b}}$, Jean-Henry Ferrasse ${ }^{\mathrm{a}}$, Sébastien Lefevre ${ }^{\mathrm{b}}$, Alain Viand ${ }^{\mathrm{b}}$, Olivier Boutin ${ }^{\mathrm{a}}$}

a Aix Marseille Univ, CNRS, Centrale Marseille, M2P2, Marseille, France

b S.A.R.L. A3i; 255 rue Gustave Eiffel, ZAC des Eoliennes; 26290 DONZERE; FRANCE

* corresponding author olivier.boutin@univ-amu.fr

\section{Abstract}

Gas holdup of water/nitrogen, water-phenol/nitrogen and water-phenol/air systems was successfully measured by a method based on the use of a differential pressure sensor installed on a bubble column reactor, in a wide domain of temperature (from 100 to $300^{\circ} \mathrm{C}$ ) and pressure (from 10 to $30 \mathrm{MPa}$ ). These experimental conditions are little or no explored in literature. Results show a predominant influence of the superficial gas velocity, the evaporation of the liquid phase, the ratio of the gas volume flowrate on the liquid volume flowrate and the phenol concentration. Pressure and chemical reaction have little effect on gas holdup. The temperature has an effect in the case of phenol solutions. The different correlations and parameters influence determined in this work are very helpful for the design of gas liquid contactors (for instance bubble column) at high pressure and high temperature.

\section{Key words}


Gas liquid contactor, gas holdup, high pressure, high temperature, bubble column

\section{Introduction}

Gas holdup is an important parameter to design liquid gas contactors because it is directly correlated with the interfacial area between the gas and the liquid phases. It depends mainly on bubbles diameter and their rising velocity. Gas holdup is high when the number of bubbles is large and their diameter is small (lower rise velocity). However, as many parameters can influence this value, it is necessary to determine the most important ones to optimize the design of this type of contactor. Literature gives a first idea of the influence of these factors, mainly under limited range of operating conditions. It is generally accepted in literature that the hydrodynamics of the bubble columns can be divided in three different regimes:

- The homogeneous regime: low superficial gas velocities, characterised by a narrow bubble size distribution;

- The heterogeneous regime: high superficial gas velocities and characterised by a large distribution of the bubble diameters;

- A transition regime between the two cited above.

The transition between the different regimes is governed mainly by the superficial gas velocity but pressure, temperature, gas distributor and column design are also reported to be relevant. As the mechanism governing the different regime are different, the operating parameters, such as pressure or temperature, are suspected to have different effect depending on the hydrodynamic regime. 
Pressure increase leads to an increase of gas holdup. This effect can be related to a decrease of the bubble's diameter, by an effect on the bubble breakup. However, in the homogeneous regime and/or for relatively low gas velocities (less than $5 \mathrm{~cm} . \mathrm{s}^{-1}$ ), some authors observe a significant increase (Tarmy et al., 1984 ; Idogawa et al., 1986; De Bruijn et al., 1988 ; Wilkinson et al., 1990 ; Wilkinson et al., 1992 ; Lin et al., 1998 ; Therning and Rasmuson, 2001; Shaikh et al., 2005; Schäfer et al., 2002; Lin et al., 2006), others a smaller increase than in the heterogeneous regime (Clark, 1990 ; Oyevaar et al., 1991 ; Krishna et al., 1991 ; Reilly et al., 1994 ; Jiang et al., 1995 ; Dewes and Schumpe, 1997; Kang et al., 1999 ; Kang et al., 2000 ; Hashemi et al., 2009 ; Pjontek et al., 2014$)$, and others observe no effect of pressure (Sangnimnuan et al., 1984 ; Letzel et al., 1997 ; Letzel et al., 1998 ; Letzel et al., 1999; Krishna and Sie, 2000 ; Ishibashi et al., 2001 ; Pohorecki et al., 2001 ; Kemoun et al., 2001 ; Chilekar, 2007 ; Chilekar et al., 2010 ; Kumar et al., 2012 ;). For example, for the water/air system, Schäfer et al. (2002) observe a significant decrease in bubble diameter by increasing pressure (up to 5MPa) in the homogeneous regime, up to a plateau at around 10MPa. These results also indicate that the effect of pressure decreases as bubble's diameter decreases. Letzel et al. $(1997,1998,1999)$ establish that only the largest bubbles are affected by pressure, which explains why no effect is observed under homogeneous conditions. Pressure effect could be mainly related to an increase in gas density (Wilkinson et al., 1990 ; Krishna et al., 1991 ; Reilly et al., 1994 ;Krishna and Ellenberger, 1996 ; Dewes and Schumpe, 1997; Letzel et al., 1998 ; Jordan and Schumpe, 2001).

Temperature increase generally leads to an increase in gas holdup and/or a decrease in bubble diameter (Sangnimnuan et al., 1984 ; Wilkinson et al., 1992 ; Soong et al., 1997 ; Lin et al., 1998 ; Luo et al., 1999; Ishiyama et al., 2001; Pohorecki et al., 2001 ; Schäfer et al., 2002 ; Lorenz et al., 2005 ; Lau et al., 2004 ; Behkish et al., 2007 ; Hashemi et al., 2009). This increase leads to a decrease in surface tension and is therefore likely to decrease the drainage rate of the liquid film, the diameter of the primary bubble and the maximum diameter of bubbles (Leonard, 2018). It also leads to two possible effects on coalescence. The decrease in liquid viscosity increases the drainage rate and the collision frequency and is therefore likely to promote coalescence. On the contrary, the 
coalescing contact time is also likely to decrease. In practice, according to the operating conditions range, the effects observed are different. Thus, Pohorecki et al. (1999) found no effect of temperature on gas holdup, which may be related to evaporation. Other authors observe a decrease in gas holdup as the temperature increases and a negative effect of temperature, at ambient pressure, between 30 and $80^{\circ} \mathrm{C}$ in the water/air system (Kölbel et al., 1971 ; Deckwer et al., 1980 ; Grover et al., 1986; Yang et al., 2001). Their holdup measurements in aqueous solutions containing dissolved salts show that temperature has a positive effect on the gas holdup. Since salts are coalescing inhibitors, it seems that the negative effect observed for salt-free system is due to the promotion of coalescence. This decrease is also observed by Kölbel et al. (1971) in homogeneous regime, whereas no effect is observed under the heterogeneous conditions.

Concerning liquid superficial velocity, Lau et al. (2004) show an effect at ambient pressure but only for high superficial gas velocity. At 4.24MPa, the superficial liquid velocity seems to have no influence. This influence seems to be limited to pressures close to atmospheric pressure and leads to a marginal decrease in gas holdup by increasing the proportion of liquid.

As for the influence of the working mode, it has been reported that gas holdup increases with liquid superficial velocity in counter current mode but decreases or remains constant in co current mode. The effect is more pronounced at high gas velocity (Bin et al., 2001 ; Jin et al., 2010). In fact, the difference between the two working mode is always lower than $2 \%$. It has no real influence on the gas holdup.

As for the influence of the superficial gas velocity, in the homogeneous regime, the average diameter of bubbles increases slightly with gas superficial velocity (Kluytmans et al., 2003). At the transition, the average diameter increases whereas in heterogeneous regime the proportion of large bubbles increases while that of small bubbles remains relatively constant. Thus, for water/air system, Fukuma et al. (1987) observe an increase in bubble diameter with superficial gas velocity in homogeneous and heterogeneous regimes. Other authors observe this increase in bubble diameter whatever the hydrodynamic regime studied 
(Smith et al., 1996 ; Majumder et al., 2006; Simmonet et al., 2007 ; Xue et al., 2008 ; Garcia-Abuin et al., 2012; Muroyama et al., 2013). Pohorecki et al. (1999) observe no effect of superficial velocity on bubble diameter under saturated conditions.

The gas distributor has a major influence at the boundary between homogeneous and transition regimes, but has no consistent effect in well-established homogeneous and heterogeneous regimes (Ohki and Inoue, 1970; Reilly et al., 1986; Zahradnik et al., 1997 ). Generally, porous or membrane distributors allow to obtain narrow size distributions and thus a better stability of homogeneous regime than the perforated distributors (Zahradnik et al., 1997 ; Krishna and Ellenberger, 1996 ; Bouaifi et al., 2001; Kantarci et al., 2005). There is no effect of the gas distributor for pressures higher than 15MPa, an effect attributed to a smaller diameter of the primary bubble (Idogawa et al., 1986).

In the homogeneous regime, the lower the height of dispersion, the higher the gas holdup is. In heterogeneous regime, dispersion height has no more influence for ratios $\mathrm{H}_{\mathrm{C}} / \mathrm{D}_{\mathrm{C}}$ higher than 5 (Wilkinson et al., 1992 ; Zahradnik et al., 1997 ; Parasu Veera and Joshi, 2000; Ruzicka et al., 2001 ; Kantarci et al., 2005 ; Lau et al., 2012).

Literature shows that a parametric study is complex as the influence of a parameter itself depends on one or more other parameters. Temperature and pressure seem to have predominant effects. However, a plateau is observed by different authors for the effects of pressure: it is therefore necessary to evaluate the effect of this parameter. Temperature is likely to have two possible effects. This parameter is therefore also estimated. Superficial velocity is obviously a parameter of interest. As the operating mode (co-current or counter current) has little effect for holdups in the range from 0.02 to 0.3 , it will not be studied. Finally, effects related to gas solubility and partial evaporation of the liquid have been identified in the literature. At the temperatures and pressures applied, gas solubility is important, and evaporation can be significant. It will therefore be essential to quantify these effects. Thus, literature offers 
many results, but often qualitative for high pressures and high temperatures. It is hence necessary to investigate the behaviour of the systems in these conditions of high pressure and temperature. Four parameters will be tested in the liquid-gas contactor: pressure, temperature and superficial velocities of gas and liquid. Finally, the effect of the chemical reaction will be quantified by measurements in reactive conditions in water-phenol/air systems. The different systems studied (water/nitrogen, water/phenol/nitrogen, water/phenol/oxygen) have been chosen because they allow to change the physical properties. The systems without oxygen allow to study an evolution without any reaction (or a very slow one due to liquefaction processus). On the contrary, the system with oxygen allow a study taking into account a variation in the composition due to the reaction. Phenol has been chosen because its modification of the physical properties is quite significant, even at low temperatures, and because its kinetics parameters are well known in these conditions (Lefèvre et al., 2011). The pressure and temperature variations have been chosen in large range but always in subcritical conditions, and the flowrate is coherent with industrial applications and needs, for instance wet air oxidation.

\section{Materials and methods}

\subsection{Measurement method}

Among the main existing methods, the most common is the measurement of pressure difference between two points of the column (Hikita and Kikukawa,

1974 ; Therning and Rasmuson, 2001 ; Boyer et al., 2002; Forret et al., 2003 ; Yang et al., 2003 ; Chaumat et al., 2005 ;Kantarci et al., 2005 ; Jin et al., 2007 ;Hashemi et al., 2009 ; Shah et al., 2012 ;Pjontek et al., 2014). The gas holdup is calculated with equation 1, resulting from pressure drop in two-phase flow, neglecting acceleration and friction pressure losses (Zahradnik et al., 1997; Tang et al., 2006; Shah et al., 2012). 


$$
\varepsilon_{\mathrm{G}}=\left(\frac{\rho_{\mathrm{L}}}{\rho_{\mathrm{L}}-\rho_{\mathrm{G}}}\right)\left(1-\frac{\Delta \mathrm{P}}{\rho_{\mathrm{L}} \mathrm{g} \Delta \mathrm{z}}\right)
$$

Neglecting pressure drop by acceleration requires that the gas and liquid superficial velocities and densities remain constant between the two points. The contactor section must be constant, and the holdup is also assumed to be constant. The transfer of matter cannot be neglected. Tang and Heindel (2006) have shown that, in general, viscous friction losses are negligible when surface velocities of gas and liquid are low ( $\mathrm{u}_{\mathrm{L}}<1 \mathrm{~cm} . \mathrm{s}^{-1}$ and $\left.\mathrm{u}_{\mathrm{G}} \approx 0-30 \mathrm{~cm} . \mathrm{s}^{-1}\right)$ and liquid viscosity are low (for example in water).

\subsection{Experimental set-up}

A general diagram of the pilot plant (Separex, France) is presented in Figure 1 . The liquid gas contactor is a cylinder of internal diameter $4 \mathrm{~cm}$ and height $83 \mathrm{~cm}$ (volume $1 \mathrm{~L}$, Inconel $625,30 \mathrm{MPa}, 350^{\circ} \mathrm{C}$ ). It is equipped with an outlet pressure sensor, a low purge valve and a vent valve. It is divided into three stages heated by an electric collar (first stage) or a heat-exchange double jacket ( $2^{\text {nd }}$ and $3^{\text {rd }}$ stages). Taps allow temperature and differential pressure measurements. After cooling, a TESCOM ${ }^{\circledR}$ pressure regulator is used to control the pressure.

The gas (nitrogen or reconstituted air $80 \% \mathrm{~N}_{2}$ and $20 \% \mathrm{O}_{2}$ ) comes from pressurized cylinders (Air Liquide, France, purity $99 \%$ ). Gas is admitted into pneumatic booster system (DLE-75-1, MAXIMATOR ${ }^{\circledR}$ ), measured by a mass flow meter (BRONKHORST El-Flow F232-M 0 to 65 NL.min ${ }^{-1}$, accuracy: $0.5 \%$ value \pm 0.065NL. $\left.\mathrm{min}^{-1}\right)$. The system is equipped with a buffer tank to absorb any oscillations of the flow. The gas is heated in a heat exchanger (1500 W electric heating collar). The regulation is made using a thermocouple measuring the temperature at the heart of the steel block. A thermocouple is placed before injection at the exit of the gas heat exchanger. The gas is injected into the column using a sintered disc. The gas distributor is mentioned as a parameter of interest. Using 
a porous medium with pore diameter of less than $100 \mu \mathrm{m}$ may be recommended for achieving good performances. For the column studied the distributor is a PORAL $^{\circledR}$-type sinter with an average pore diameter of $80 \mu \mathrm{m}$ (class 30 ). It must be ensured that the zone of the distributor does not have any influence on the overall hydrodynamics of the column. Working with ratios $\mathrm{H}_{\mathrm{C}} / \mathrm{D}_{\mathrm{C}}>5$ and $\mathrm{z} / \mathrm{D}_{\mathrm{C}}>5$ is therefore necessary. These conditions are checked for the column used in this study. Superficial gas velocity is calculated from the booster outflow $\left(\mathrm{QG}^{\circ}\right.$ in NL.min $\left.^{-1}\right)$ with equation 2.

$$
\mathrm{u}_{\mathrm{G}}=\frac{\mathrm{Q}_{\mathrm{v}, \mathrm{G}}}{\mathrm{S}_{\mathrm{C}}}=\frac{\frac{\mathrm{Q}_{\mathrm{G}}{ }^{\circ}}{1000 \times 60} \rho_{\mathrm{G}}{ }^{\circ}}{\rho_{\mathrm{G}} \mathrm{S}_{\mathrm{C}}}
$$

Density $\rho_{\mathrm{G}}{ }^{\circ}$ is nitrogen density under normal conditions. During the experiments, temperature varies between 100 and $250^{\circ} \mathrm{C}$ and pressure between 10 and $30 \mathrm{MPa}$. At $10 \mathrm{MPa}$, the superficial velocity range is 0.20 to $1.70 \mathrm{~cm} . \mathrm{s}^{-1}\left(0.1\right.$ to $0.88 \mathrm{~cm} . \mathrm{s}^{-1}$ at $20 \mathrm{MPa}$ and 0.08 to $0.65 \mathrm{~cm} . \mathrm{s}^{-1}$ at $\left.30 \mathrm{MPa}\right)$. The gas flow rate is also measured after phase separation, expansion and cooling, with a hot wire gas flowmeter.

The liquid pump is a piston pump (SEPAREX LGP50, France) with flowrates from 0 to $120 \mathrm{~g} . \mathrm{min}^{-1}$, up to $100 \mathrm{MPa}$. The liquid is heated by a $6000 \mathrm{~W}$ ceramic collar. Temperature at the exchanger outlet is monitored using a thermocouple. The liquid is injected at the bottom of the column, above the sintered material. Liquid and gas work in co-current. The superficial liquid velocity in the column is calculated from the outflow from the pump ( $\mathrm{Q}_{\llcorner}^{\circ}$ in g.min $\left.{ }^{-1}\right)$ using equation 3. The range studied is 0.04 to $0.16 \mathrm{~cm} \cdot \mathrm{s}^{-1}$.

$$
\mathrm{U}_{\mathrm{L}}=\frac{\mathrm{Q}_{\mathrm{V}, \mathrm{L}}}{\mathrm{S}_{\mathrm{C}}}=\frac{\frac{\mathrm{Q}_{\mathrm{L}}^{\circ}}{1000 \times 60}}{\rho_{\mathrm{L}} \mathrm{S}_{\mathrm{C}}}
$$




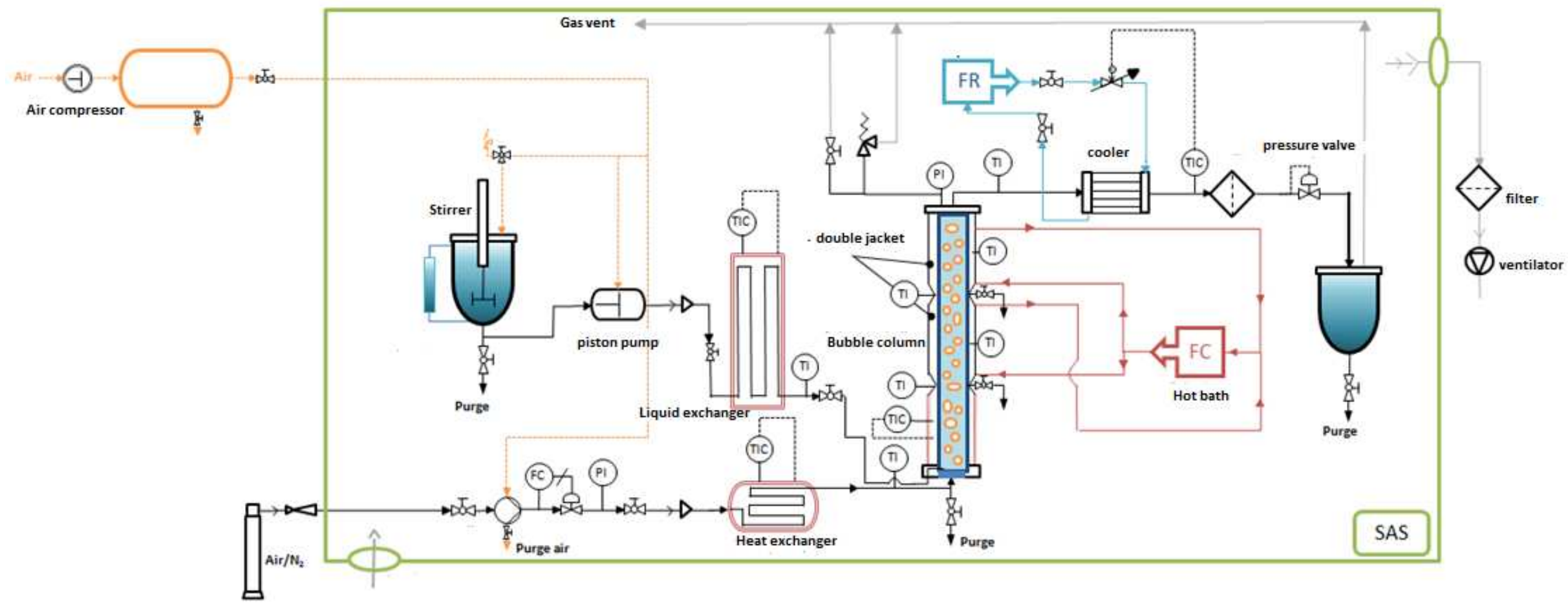

Figure 1: Simplified diagram of the pilot plant used for holdup measurements. 


\subsection{Gas holdup calculation}

The differential pressure sensor is a FKCT-43 (FUJI ELECTRIC, $0-4800 \mathrm{~Pa}, 42 \mathrm{MPa}, 120^{\circ} \mathrm{C}$, accuracy \pm $0.065 \%$ of the measuring range: $\pm 3.12 \mathrm{~Pa}$ ). It is connected to the column via taps allowing measurement in the second stage, in the third stage or in the second and third stages simultaneously.

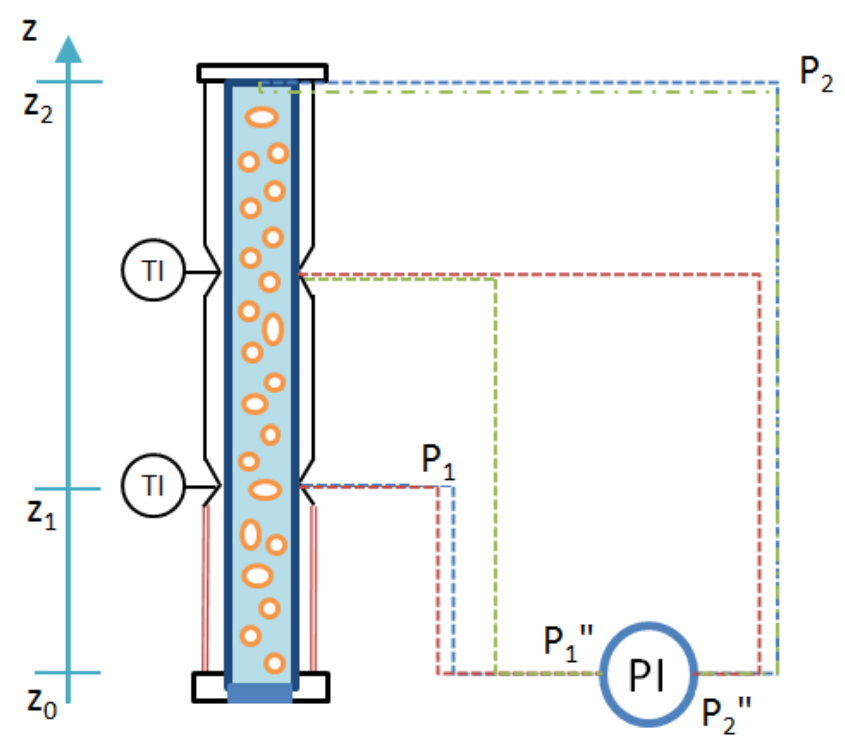

Figure 2: Schematic diagram of the measuring apparatus. Red: measurement in the $2^{\text {nd }}$ stage. Green: measurement in the $3^{\text {rd }}$ stage. Blue: simultaneous measurement in $2^{\text {nd }}$ and $3^{\text {rd }}$ stage.

The static pressure drop in the tubes connecting the sensor to the column (Figure 2) implies a modification of equation 2. For instance, let us consider the case of the measurement between the second and third stages simultaneously. The sensor measures the differential pressure drop given by equations 4 and 5 . It is valid if the density $\rho$ in the connection tubes, filled with liquid, can be considered constant along the vertical axis. The bend is set with a sufficient length from the column so that the temperature at the elbow equals the ambient temperature. Tests have been carried out and it appears that a length of $50 \mathrm{~cm}$ is sufficient to satisfy this condition.

$$
\begin{aligned}
& \Delta \mathrm{P}_{\mathrm{m}}=\mathrm{P}_{2}^{\prime \prime}-\mathrm{P}_{1}^{\prime \prime}=\mathrm{P}_{2}-\mathrm{P}_{1}+\rho \mathrm{g}\left(\mathrm{z}_{2}-\mathrm{z}_{1}\right) \\
& \Delta \mathrm{P}_{\mathrm{m}}=\mathrm{g}\left(\mathrm{z}_{2}-\mathrm{z}_{1}\right)\left[-\rho_{\mathrm{L}}\left(1-\varepsilon_{\mathrm{G}}\right)-\rho_{\mathrm{G}} \varepsilon_{\mathrm{G}}+\rho_{\mathrm{L}}\left(\mathrm{T}_{\mathrm{atm}}\right)\right]
\end{aligned}
$$

The zero of the pressure sensor is given by equation 6 , leading to equation 7 . 


$$
\begin{aligned}
& \Delta \mathrm{P}_{\mathrm{m}, 0}=\mathrm{g}\left(\mathrm{z}_{2}-\mathrm{z}_{1}\right)\left[-\rho_{\mathrm{L}}\left(\mathrm{T}_{\mathrm{zero}}\right)+\rho_{\mathrm{L}}\left(\mathrm{T}_{\mathrm{atm}}\right)\right] \\
& \Delta \mathrm{P}_{\mathrm{m}}=\mathrm{g}\left(\mathrm{z}_{2}-\mathrm{z}_{1}\right)\left[-\rho_{\mathrm{L}}\left(1-\varepsilon_{\mathrm{G}}\right)-\rho_{\mathrm{G}} \varepsilon_{\mathrm{G}}+\rho_{\mathrm{L}}\left(\mathrm{T}_{\text {zero }}\right)\right]
\end{aligned}
$$

The influence of temperature increase during the passage of the gas is considered through the difference of liquid densities. The gas holdup is finally given by equation 8 .

$$
\varepsilon_{G}=\frac{\Delta P_{m}}{g\left(z_{2}-z_{1}\right)\left(\rho_{L}-\rho_{G}\right)}+\frac{\rho_{L}-\rho_{L}\left(T_{\text {zero }}\right)}{\rho_{L}-\rho_{G}}
$$

Equation 8 can be applied if densities (at $\mathrm{T}$ and $\mathrm{T}_{\text {zero }}$ ) are constant in the column. This condition is verified if there is no temperature gradient or composition change in the column. For inert systems it is easy to validate this condition. However, in water-phenol/air system, the chemical reaction can induce temperature gradients and change in density. The influence of temperature can be considered by using thermocouples, located at the same level of the pressure taps. Considering the variation of density requires integrating equation 9.

$$
\frac{\partial P}{\partial z}=-g\left[\rho_{L}\left(1-\varepsilon_{G}\right)+\rho_{G} \varepsilon_{G}\right]
$$

Equations 5 and 8 were established assuming a constant pressure drop by friction and acceleration in the column, assumptions verified in Appendix A. Similarly, the quantification of the effects of liquid evaporation and solubility of gases are given in Appendix B. The quantification of pressure drop by acceleration is validated in Appendix C.

\subsection{Experimental procedure}

The reactor is filled at ambient temperature and pressure with the solution. The connecting tubes of the pressure sensor are purged of any residual gas. The reactor is pressurized and heated. Once temperatures are stable, acquisition starts, the sensor zero is set and a temperature measurement is done to consider the basic temperature gradient in the column. Gas is then admitted into the column. When the permanent regime is reached, the holdup can be calculated from the $\Delta \mathrm{P}$ signal. 
Uncertainties on the measured holdups are evaluated from reproducibility tests carried out for each pressure. The uncertainties obtained at a fixed low gas flow rate of $10 \mathrm{NL}$. $\mathrm{min}^{-1}$ are important because the measured pressure drop rarely exceeds $40 \mathrm{~Pa}$ and the holdup is low. For these flows, the uncertainties vary between 7.7 and $36.1 \%$ with an average of $16.8 \%$. For larger flows, the average uncertainty is lower: $3.9 \%$ at $10 \mathrm{MPa}, 3.6 \%$ at $20 \mathrm{MPa}$ and $8.5 \%$ at $30 \mathrm{MPa}$. Uncertainties on superficial gas velocity are evaluated from the uncertainties on the average flow and gas density in the column. Relative uncertainties range from 0.6 to $7.3 \%$ with an average of $2.2 \%$. The relative uncertainties on superficial liquid velocity are low (less than $1 \%$ ).

82 measurements were made on water/nitrogen system: 49 measurements in the second and third stages simultaneously, 23 in the second stage and 10 in the third stage. 7 tests were carried out in water-phenol/nitrogen system ( 2 tests at $2 \mathrm{~g} \cdot \mathrm{L}^{-1}$ and 5 tests at $\left.29 \mathrm{~g} \cdot \mathrm{L}^{-1}\right) .17$ measurements were made in water-phenol/air system: 3 tests at $2 \mathrm{~g} \cdot \mathrm{L}^{-1}, 6$ tests at $10 \mathrm{~g} \cdot \mathrm{L}^{-1}, 7$ tests at $30 \mathrm{~g} \cdot \mathrm{L}^{-1}$ and 1 test at $80 \mathrm{~g} \cdot \mathrm{L}^{-1}$. Measurements in water-phenol/nitrogen and water-phenol/air systems were performed in the $2^{\text {nd }}$ and $3^{\text {rd }}$ stages simultaneously.

\section{Results and discussions}

\subsection{Measurements with the water/nitrogen system}

The results of temperature-dependent gas hold up in water/nitrogen system are shown in Figures D1 to $\mathrm{D} 3$, Appendix D. At $10 \mathrm{MPa}$ and $100^{\circ} \mathrm{C}$, gas holdup is a linear function of superficial gas velocity and is constant in the column. The superficial velocity of liquid has no influence. At $175^{\circ} \mathrm{C}$, gas holdup appeared to be higher than at $100^{\circ} \mathrm{C}$ for high gas velocities $\left(u_{G}>0.5 \mathrm{~cm} \cdot \mathrm{s}^{-1}\right)$. The liquid flow has no influence $\left(u_{G}<0.5 \mathrm{~cm} \cdot \mathrm{s}^{-1}\right)$. At $200^{\circ} \mathrm{C}$, gas holdup is identical to that obtained at $100^{\circ} \mathrm{C}$ for $\mathrm{u}_{\mathrm{G}}<0.8 \mathrm{~cm} \cdot \mathrm{s}^{-1}$. It is higher at $200^{\circ} \mathrm{C}$ than at $175^{\circ} \mathrm{C}$ and $100^{\circ} \mathrm{C}$, again indicating a positive effect of temperature, linked 
with the evolution of viscosity and surface tension (Leonard, 2018). The liquid flow has no influence for $u_{G}<1.0 \mathrm{~cm} \cdot \mathrm{s}^{-1}$. At $240^{\circ} \mathrm{C}$, gas holdup is higher than at other temperatures, regardless of the range of $\mathrm{u}_{\mathrm{G}}$.

These different evolutions indicate that the superficial liquid velocity has a predominant influence on gas holdup, which is lower when superficial velocity is higher. The effect of $u_{L}$, however, is weaker at low $u_{G}$. For fixed conditions of pressure, temperature and liquid flow, gas holdup remains a linear function of $u_{G}$. The effect of temperature is preponderant: between 200 and $240^{\circ} \mathrm{C}$, gas holdup is almost doubled at the highest superficial gas velocity. The effect of pressure is less significant, as its influence on viscous and surface tension values is less important. At 20 and $30 \mathrm{MPa}$, the superficial liquid velocity does not seem to play a dominant role, except at low gas velocity where the holdup appears to be higher at high superficial liquid velocity. Gas holdup is not a linear function of $u_{G}$, but the curve becomes clearly convex. This effect is more important when $\mathrm{u}_{\mathrm{G}}$ is important $\left(>0.8 \mathrm{~cm} \cdot \mathrm{s}^{-1}\right)$ and $Q_{\mathrm{L}}^{0}$ is low. It seems to induce a slight increase in holdup in the third stage of the column.

Finally, the effect of the superficial liquid velocity observed at 20MPa at low gas velocity (higher holdup at high liquid velocity) appears to be in contradiction with that observed at 10 and $30 \mathrm{MPa}$. In fact, it is possible that partial evaporation at highest liquid flowrate and high pressure (for $\mathrm{u}_{G}<0.2 \mathrm{~cm} . \mathrm{s}^{-1}$ ) has more effects because $u_{L}$ and $u_{G}$ are of the same order of magnitude. In view of these remarks, this effect is linked to the partial evaporation of the liquid phase.

Pressure influence on gas holdup is shown in Figures E1 and E2 in Appendix E. At $100^{\circ} \mathrm{C}, 10$ and $20 \mathrm{MPa}$, liquid velocity has no influence on gas holdup. It does not seem to depend on pressure: it only depends on $\mathrm{u}_{\mathrm{G}}$. At $200^{\circ} \mathrm{C}$, between 20 and $30 \mathrm{MPa}$, the holdup seems constant for $\mathrm{u}_{\mathrm{G}}<0.8 \mathrm{~cm} \cdot \mathrm{s}^{-1}$ : it does not depend on the pressure at low gas velocities. In the same superficial velocity range, holdup does not depend on the liquid flowrate and is constant in the column. At $10 \mathrm{MPa}$ it is higher than at 20 and $30 \mathrm{MPa}$ throughout the superficial gas velocity range, although the difference is smaller at low gas velocity $\left(u_{G}<0.8 \mathrm{~cm} \cdot \mathrm{s}^{-1}\right)$. For high gas velocities, the same increase is found when the liquid flowrate 
decreases. At $15 \mathrm{MPa}$, the holdup in the second stage is equal to that obtained at $10 \mathrm{MPa}$ in the same stage, indicating a negligible effect of the pressure between 10 and $15 \mathrm{MPa}$. For $\mathrm{u}_{\mathrm{G}}<0.8 \mathrm{~cm} \cdot \mathrm{s}^{-1}$, the pressure has a slight effect of decreasing holdup from $20 \mathrm{MPa}$. At $240^{\circ} \mathrm{C}$, between 20 and $30 \mathrm{MPa}$, it seems constant for $\mathrm{u}_{\mathrm{G}}<1.0 \mathrm{~cm} \cdot \mathrm{s}^{-1}$ : holdup does not therefore depend on the pressure between 20 and $30 \mathrm{MPa}$ at low gas velocities. In the same superficial velocity range, the holdup does not depend on the liquid flowrate. These results are similar to those obtained at $200^{\circ} \mathrm{C}$ but in a wider range of $\mathrm{u}_{\mathrm{G}}$. Gas holdup decreased between 10 and $20-30 \mathrm{MPa}$ throughout the range of surface velocity tested. The effect of temperature is therefore predominant only at low pressure. This is confirmed by the evolution of surface tension with pressure and temperature (Leonard, 2018) The effects of liquid velocity discussed previously are the same in this case. In summary, the different trends can be summarized in Table 1. 


\begin{tabular}{|c|c|c|c|}
\hline \multicolumn{4}{|c|}{$P=10 \mathrm{MPa}$} \\
\hline $\begin{array}{l}\text { U } \text { range/ } \\
\text { Parameters }\end{array}$ & $0.1-0.5$ & $0.5-1.0$ & $1.0-1.8$ \\
\hline$u_{G}$ & $\uparrow$ & $\uparrow$ & $\uparrow$ \\
\hline \multirow{2}{*}{$T\left({ }^{\circ} \mathrm{C}\right)$} & $\pi[100-200]$ & $\pi[100-200]$ & $\pi[100-200]$ \\
\hline & $\uparrow[200-240]$ & $\uparrow[200-240]$ & $\uparrow[200-240]$ \\
\hline$Q_{\llcorner}^{\circ}\left(\mathrm{g} \cdot \mathrm{min}^{-1}\right)$ & $\begin{array}{l}100-200^{\circ} \mathrm{C}: \emptyset[25-100] \\
200-240^{\circ} \mathrm{C}: \searrow[25-100]\end{array}$ & $\begin{array}{l}100-200^{\circ} \mathrm{C}: \emptyset[25-100] \\
200-240^{\circ} \mathrm{C}: \downarrow[25-100]\end{array}$ & $\begin{array}{r}100-200^{\circ} \mathrm{C}: \\
\varnothing[25-50] \\
\varnothing[50-100]\end{array}$ \\
\hline \multicolumn{4}{|c|}{$P=20 \mathrm{MPa}$} \\
\hline $\begin{array}{l}\text { UG range/ } \\
\text { Parameters }\end{array}$ & $0.1-0.4$ & $0.4-0.8$ & $0.8-1.0$ \\
\hline$u_{G}$ & $\uparrow$ & $\uparrow$ & $\uparrow$ \\
\hline$T\left({ }^{\circ} \mathrm{C}\right)$ & $\varnothing[100$ - 240] & $\begin{array}{l}\varnothing[100-200] \\
\uparrow[200-240]\end{array}$ & $\begin{array}{l}\varnothing[100-200] \\
\uparrow[200-240]\end{array}$ \\
\hline$Q_{L^{\circ}}\left(\mathrm{g} \cdot \mathrm{min}^{-1}\right)$ & $100-240^{\circ} \mathrm{C}: \varnothing[25-100]$ & $100-240^{\circ} \mathrm{C}: \varnothing[25$ - 100] & $\begin{array}{r}100-200^{\circ} \mathrm{C}: \emptyset[25-100] \\
200-240^{\circ} \mathrm{C}: \\
\searrow[25-50] \\
\varnothing[50-100]\end{array}$ \\
\hline
\end{tabular}

$P=30 \mathrm{MPa}$

\begin{tabular}{c|c}
\hline$u_{\mathrm{G}}$ range/ & $0.1-0.8$ \\
Parameters & \\
\hline$u_{\mathrm{G}}$ & $\uparrow$ \\
\hline$T\left({ }^{\circ} \mathrm{C}\right)$ & $\varnothing[100-240]$ \\
\hline$Q_{L^{\circ}}$ & $100-240^{\circ} \mathrm{C}: \varnothing[25-100]$
\end{tabular}

Table 1: Influence of operating parameters on gas holdup. $\varnothing$ : no effect. $\nearrow$ : little increase. $\uparrow:$ increase. $\searrow$ : little decrease.

$\downarrow$ : decrease. The trends are reported for an increase of the parameter. 

The lack of pressure effect may agree with the presence of plateau observed from ambient up to $10 \mathrm{MPa}$ in the literature. The absence of temperature effects may be due to the presence of small bubbles related to an efficient distributor and a limitation of coalescence by pressure. The effect of superficial gas velocity agrees with literature.

As discussed before, the effects of temperature and pressure appear to be mainly related to the effect of gas saturation by water vapor. It is possible to assume that the effects of temperature and $\mathrm{u}_{\llcorner}$on gas holdup are only related to evaporation. To quantify this effect, the complete saturation of the gas by water vapour is assumed. In this case, it is possible to estimate the superficial gas and liquid velocities with equations 10 to 12 .

$$
\begin{aligned}
& u_{G, \text { sat }}=u_{G}+\frac{Q_{v, v a p}}{S_{C}} \\
& u_{L, s a t}=u_{L}-\frac{Q_{v, v a p} \rho_{v a p}(T, P)}{S_{C} \rho_{L}} \\
& \text { with } Q_{v, v a p}=\frac{y_{v, H 2 O}}{1-y_{v, H 2 O}} Q_{v, N 2}
\end{aligned}
$$

The calculation of the fraction of water vapor at the equilibrium $\mathrm{y}_{\mathrm{v}, \mathrm{H} 2 \mathrm{O}}$ is detailed on Appendix $\mathrm{B}$.

At saturation, the water losses are low enough to never drain completely the liquid. The plot of gas holdup versus saturated gas surface velocity $\left(\mu_{\mathrm{G}, \text { sat }}\right)$ for all conditions is shown in Figure 3. 


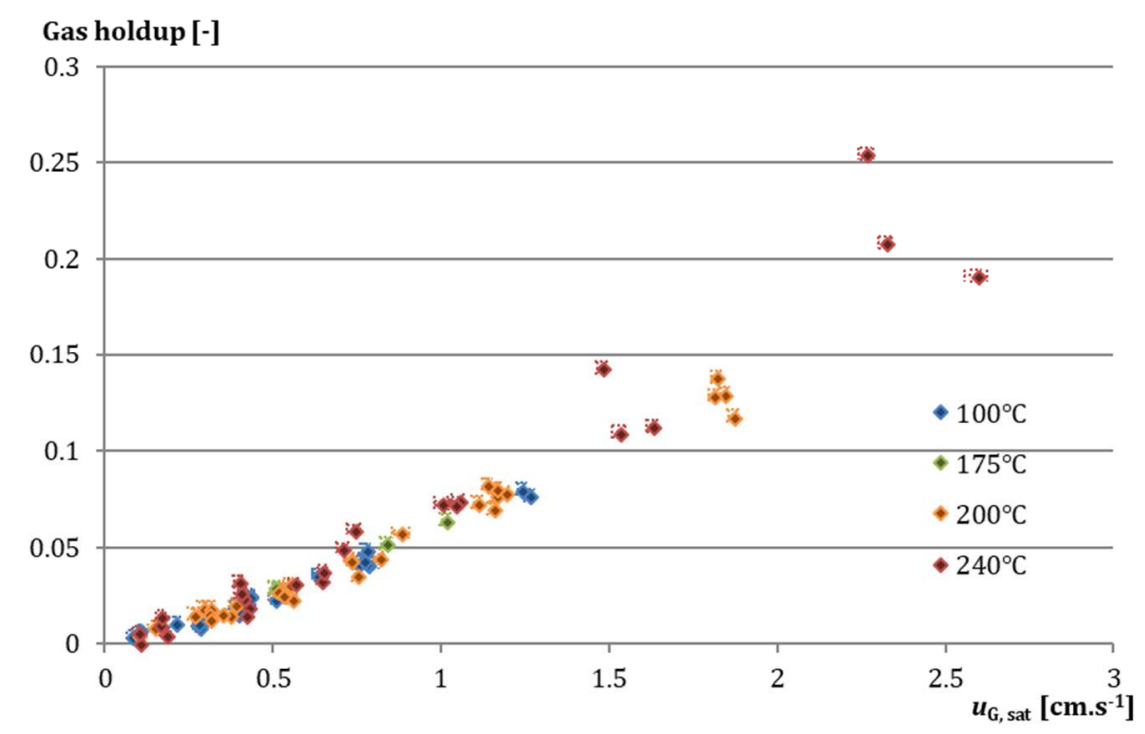

Figure 3: Evolution of gas holdup as a function of gas superficial velocity under saturated conditions.

Figure 3 indicates that most of experimental points are correlated with superficial gas velocity under saturated conditions. For these points, $\mathrm{u}_{\mathrm{G}}$ sat could have an influence on the holdup. Some points do not agree with this trend. These points are obtained at 200 and $240^{\circ} \mathrm{C}$ for different pressures and for mass flowrates of water at the inlet of columns less than $50 \mathrm{~g} \cdot \mathrm{min}^{-1}$. The coupled effect of temperature and superficial liquid velocity is therefore not completely explained by an effect of increasing the volume flowrate of gas by saturation. Gas holdup can be calculated from interstitial gas velocity and superficial gas velocity with equation 13.

$$
\varepsilon_{\mathrm{G}}=\frac{\mathrm{u}_{\mathrm{G}}}{v_{\mathrm{G}}}=\frac{\mathrm{u}_{\mathrm{G}}}{\mathrm{u}_{\mathrm{B}}}
$$

The interstitial velocity of the gas is the rising velocity of bubbles. It is possible that the coupled effect of temperature and superficial liquid velocity is related to an evolution of $\mathrm{u}_{G} / \mathrm{u}_{\llcorner}$ratio with saturation. The points indicated above are obtained under conditions where this ratio is important and higher than $15-20$ under saturated conditions. The ratio is less than 10 in the case of other manipulations. A decrease in gas holdup is therefore observed when the proportion of liquid increases, which is in agreement with some results from literature (Chaumat et al., 2005 ; Simmonet et al., 2007 ; Jin et al., 
2007 ; Kumar et al., 2012 ; Kumar et al., 2012; Pjontek et al., 2014 ). These studies show that it is possible to model the influence of evaporation by a relation considering $\mathrm{u}_{\mathrm{G}}$, sat.

The absence of pressure and temperature effects under conditions of low superficial velocities between 20 and $30 \mathrm{MPa}$ and the presence of significant temperature effects, especially for $u_{G}>0.6 \mathrm{~cm} . \mathrm{s}^{-}$ ${ }^{1}$, could indicate that the hydrodynamic regime changes by increasing gas velocity at high temperature. For water / air system, Han and Al-Dahhan (2007) showed that transition velocity between homogeneous and transition regime is around $15 \mathrm{~cm} \cdot \mathrm{s}^{-1}$ at pressures up to $1 \mathrm{MPa}$.

Ruzicka et al. (2001) developed a model that predicts results on regime transition. In their model, homogeneous holdup is only a function of superficial gas velocity. They assume that the bubble passage induces a movement of the liquid downwards. The displaced volume, called drift volume, is expressed as a function of a portion marked $\zeta$ of the bubble. For a non-deformable sphere, the $\zeta$ portion of the bubble can be calculated as the ratio of the vertical component of Basset force to the density of the surrounding liquid (Benjamin, 1986). Ruzicka et al. (2001) recommend determining graphically $\zeta$ from holdup results. In homogeneous regime their model includes two parameters, $\zeta$ and the ascending terminal velocity of the bubbles $u_{B, \infty}$, related to the holdup by the equation 14 .

$$
\frac{1}{\varepsilon_{\mathrm{G}}}=(1+\zeta)+\left(\frac{1}{\mathrm{u}_{\mathrm{B}, \infty}}\right)\left(\frac{\mathrm{u}_{\mathrm{G}}\left(1-\epsilon_{\mathrm{G}}\right)}{\varepsilon_{\mathrm{G}}{ }^{2}}\right)
$$

The plot of the curve $1 / \varepsilon_{G}$ as a function of the ratio $u_{G}\left(1-\varepsilon_{G}\right) / \varepsilon_{G}{ }^{2}$ (Figure 4 ) is a straight line, which gives access to the terminal velocity and the parameter $\zeta$. In heterogeneous regime, the holdup is predicted simply by the plot of Zuber and Findlay: $u_{G} / \varepsilon_{G}$ as a function of $u_{G}$ is a straight line. To check the regime, these two equations were tested. Ruzicka plot predicts well the experimental points at 10, 20 and $30 \mathrm{MPa}$, whatever the operating conditions studied but for $\mathrm{u}_{\mathrm{G}}>0.5 \mathrm{~cm} \cdot \mathrm{s}^{-1}$ (Figure 4). 


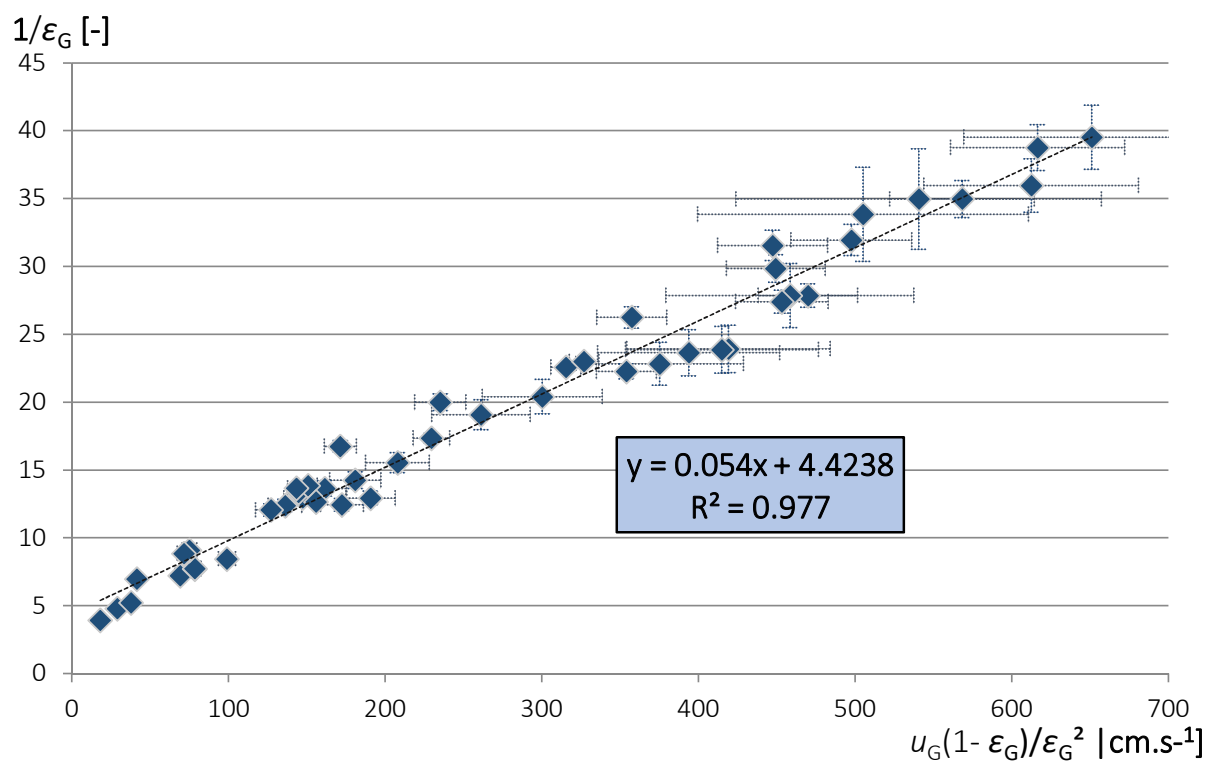

Figure 4: Ruzicka et al. (2001) model verification in homogeneous regime - water/nitrogen system with $u_{\mathrm{G}}>0,5 \mathrm{~cm} \cdot \mathrm{s}^{-1}$.

The inaccuracy on the abscissa is important for the large values of the ratio $u_{G}\left(1-\varepsilon_{G}\right) / \varepsilon_{G}{ }^{2}$ for which the holdup is low. Indeed the dependence of the term in $1 / \varepsilon_{G}{ }^{2}$ gives high uncertainty. The model, however, predicts well the results, confirming that the regime is homogeneous. The parameters obtained by regression are $\zeta=3.3 \pm 0.4$ and $\mathrm{u}_{\mathrm{B}, \infty}=18.5 \pm 0.4 \mathrm{~cm} \cdot \mathrm{s}^{-1}$. The maximum value is obtained at low gas flow $\left(Q_{G}{ }^{\circ}=10 N L \cdot \min ^{-1}\right)$ then decreases with increasing gas velocity. Given the uncertainty in estimating the rising rate of bubbles at low gas flowrate, Ruzicka et al. (2001) predicts that at low flowrates, bubbles move at the terminal velocity. They rise in the column without interactions with their neighbours. Decreasing the rising rate with gas velocity indicates that interactions increase as the density of bubbles increases, which seems consistent. This agrees with Baz-Rodríguez et al. (2014) results. The saturated plot (Appendix F) leads to similar regression parameters $\left(\zeta=3.5 \pm 0.4\right.$ and $u_{B, \infty}=$ $\left.19.2 \pm 0.4 \mathrm{~cm} \cdot \mathrm{s}^{-1}\right)$.

These results can also be obtained from the methods of Wallis (1969) and Zuber\&Findlay (1965)The Wallis plot for experiments at 10MPa (Figure E3, Appendix E) shows that the curve shape is different according to operating conditions (temperature, liquid superficial velocity). The curve shape is however always concave and never indent. This indicates that the hydrodynamic regime is 
homogeneous. This regime is better stabilized and the holdup at the transition is more important for the manipulations with high temperature (with constant flow of liquid).

Zuber and Findlay plot for holdup manipulations at 10MPa shows that no minimum is observed (Figure E4, appendix E). The curves are decreasing or almost constant (for example at $240^{\circ} \mathrm{C}-100 \mathrm{~g} \cdot \mathrm{min}^{-1}$ ). This plot confirms that the flow regime is homogeneous. Plotting under saturated conditions leads to the same conclusions.

\subsection{Gas hold up measurement in water-phenol systems}

The results obtained in the water-phenol/nitrogen and water-phenol/air systems are shown in Figure 5. The dew point of aqueous phenol solution and saturation pressure are known using ProSim $^{\circledR}$ software. Phenol fractions and reaction intermediates in the gas phase are neglected, given the small molar fraction of phenol in the gas phase. Under these conditions, the saturation pressure of waterphenol system being like that of water, the calculation of $\mathrm{U}_{\mathrm{G}}$, sat is strictly identical to that performed for water/nitrogen system. The results obtained in water-phenol/nitrogen and water-phenol/air systems are presented in Figure 5. For these systems, the composition induces a change in the surface tension value. The surface tension of the water-phenol mixture decreases as the phenol mass fraction increases (Léonard, 2018). 


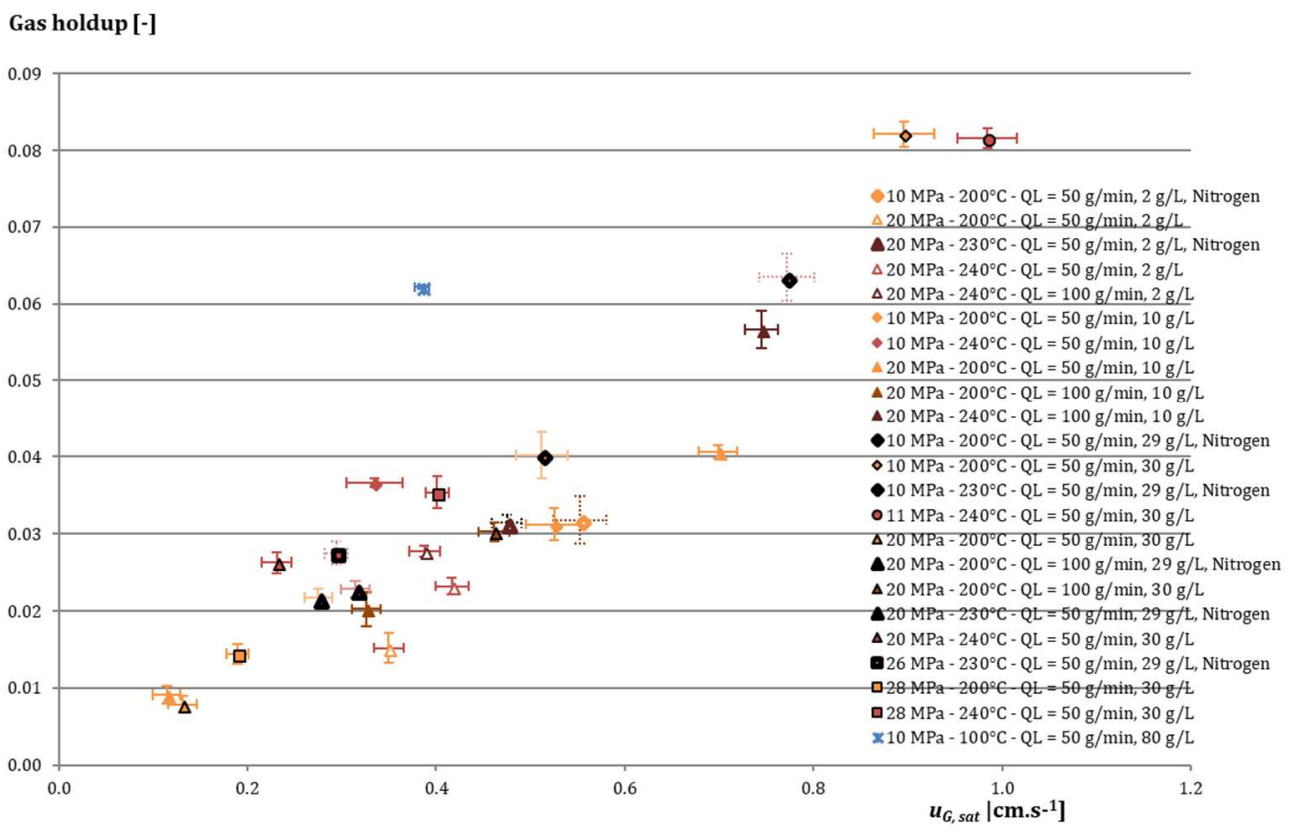

Figure 5: Experimental gas holdup for water/phenol system.

The relative uncertainties vary between 0.3 and $13.6 \%$ with an average of $5.8 \%$. The highest uncertainties are, as for water/nitrogen system, obtained with the lowest flowrates (about 15NL.min $\left.{ }^{1}\right)$. The uncertainty on superficial liquid velocity is about $5 \%$.

For the water-phenol/air systems, the influence of the chemical reaction on the superficial gas and liquid is estimated from the measurement of the concentrations of each compound at each stage. These measurements are made from direct sampling in the column and determination of the composition from gas chromatography analysis. The evolution of the different concentrations and temperature are well described in Lefèvre et al. (2011). A simple material balance shows that $u_{\mathrm{g}}$ and $\mathrm{u}_{\mathrm{I}}$ remain nearly constant in the column. The maximum variation is $3 \%$ for $u_{g}$ and $1.6 \%$ for $u_{L}$. This is explained by the production of $\mathrm{CO}_{2}$ in quasi-stoichiometric quantity compared to the oxygen loss for the gas phase and by the production of water and acetic acid in the liquid phase that compensate the phenol consumption.

Figure 5 shows that reactive system measurements follow the same trends as the inert system. For each concentration series, there is an effect of temperature which induces a holdup increase in the 
column. This effect is observed in reactive conditions or not. It is particularly visible on experiments at $2 \mathrm{~g} \cdot \mathrm{L}^{-1}$ in nitrogen or air, at the two points performed at $240^{\circ} \mathrm{C}$, to $10 \mathrm{~g} \cdot \mathrm{L}^{-1}$ and experiments at 29 and 30 $\mathrm{gL}^{-1}$ in the range $0.2-0.6 \mathrm{~cm} \cdot \mathrm{s}^{-1}$. Only one point, obtained with nitrogen at $230^{\circ} \mathrm{C}$ to $30 \mathrm{~g} \cdot \mathrm{L}^{-1}$ seems to disagree with this trend. This effect of temperature seems to disappear at high gas velocities. As for water/nitrogen system, this effect could be related to gas and liquid proportions and $u_{G} / u_{\llcorner}$ratio. Unlike water/nitrogen system, however, it is observed for lower ratios, ranging from 1.5 to 15.8 . This effect is related to the presence of phenol. Finally, as for pure water, the pressure seems to have little effect, the points obtained at 10 and 20,26 or $28 \mathrm{MPa}$ being aligned for a given temperature at each concentration.

Phenol concentration plays a major role in gas holdup, in reactive system or not. Figure 5 indicates that holdups obtained at $30 \mathrm{~g} \cdot \mathrm{L}^{-1}$ and $80 \mathrm{~g} \cdot \mathrm{L}^{-1}$ are systematically higher than those obtained at 2 and $10 \mathrm{~g} \cdot \mathrm{L}^{-1}$ at the three temperatures and regardless pressure and superficial liquid velocity. This trend is mostly observed in a narrow range of superficial gas velocity at saturation, in the range $0.2-0.7 \mathrm{~cm} \cdot \mathrm{s}^{-1}$. The presence of phenol induces a decrease in surface tension (Léonard et al., 2018). This effect can influence the diameter of the primary bubble and coalescence. A coalescence inhibiting and stabilizing effect of the homogeneous regime, identical to that of alcohols in aqueous solution, is also envisaged. The coupled effect of temperature and the presence of phenol may be related to a decrease in the rate of coalescence.

Most of the points obtained in nitrogen are perfectly in agreement with those obtained in air. Only one point, obtained at $20 \mathrm{MPa}, 230^{\circ} \mathrm{C}$ and $30 \mathrm{~g} \cdot \mathrm{L}^{-1}$ does not correspond in the non-reactive system. However, for this experiment, the oxygen consumption is much higher $(75 \%)$ than for other experiments (less than $50 \%$ consumption). This may indicate that some bubbles are reduced in size and ascend slower. Anyway, in most cases, the oxygen loss does not seem to have any influence. The lack of effect of the chemical reaction indicates that the presence of phenol or its disappearance in the upper stages of the column does not play a predominant role on gas holdup. The effect of phenol may be related to a smaller and stable primary bubble. It is also possible that the surface tension of phenol 
solutions remains sufficiently low during the production of reaction intermediates and acetic acid, resulting in low levels of coalescence (acetic acid has a lower surface tension than phenol) (Leonard; 2018).

Considering that the $\mathrm{CO}_{2}$ in the liquid phase leads to less than $4 \%$ error in superficial gas velocity at saturation for most of the points, except for two points at $30 \mathrm{~g} \cdot \mathrm{L}^{-1}\left(9.3 \%\right.$ at $20 \mathrm{MPa}-240^{\circ} \mathrm{C}-\mathrm{Q}_{\mathrm{L}}^{\circ}=$ 50g. $\mathrm{min}^{-1}$ and $6 \cdot 6 \%$ at $20 \mathrm{MPa}-200^{\circ} \mathrm{C}-\mathrm{Q}_{\mathrm{L}}^{\circ}=50 \mathrm{~g} \cdot \mathrm{min}^{-1}$ ) for which conversion is important. This can induce a lower real velocity and thus more effects of the chemical reaction, related to the loss of gas. In fact, taking limit case $\left(20 \mathrm{MPa}-240^{\circ} \mathrm{C}-\mathrm{Q}_{\mathrm{L}}^{\circ}=50 \mathrm{~g} \cdot \mathrm{min}^{-1}\right)$, the partial pressure of $\mathrm{CO}_{2}$ in the gas phase (at the column outlet, if all the $\mathrm{CO}_{2}$ has passed into the gas phase) is $1.86 \mathrm{MPa}$. Under these conditions the solubility of $\mathrm{CO}_{2}$ in water, predicted by the Himmelblau equation (Himmelblau, 76) is $20.17 \mathrm{~mol} . \mathrm{m}^{-}$ ${ }^{3}$. Considering an initial zero $\mathrm{CO}_{2}$ concentration, the molar flow rate lost by solubility is $1.68 .10^{-5} \mathrm{~mol} . \mathrm{s}^{-}$ ${ }^{1}$. This value is much lower than the molar flowrate produced $\left(1.32 .10^{-3} \mathrm{~mol}^{-1}\right)$, indicating that most of the $\mathrm{CO}_{2}$ goes is transferred to the gas phase.

To determine the hydrodynamic regime in the water-phenol system, Ruzicka et al. (2001) plot is carried out under conditions of identical $\mathrm{u}_{\mathrm{G}}$ with respect to water/nitrogen system in order to be able to compare the regression parameters $\left(u_{G}>0.5 \mathrm{~cm} \cdot \mathrm{s}^{-1}\right)$. $\mathrm{u}_{\mathrm{G}}$ values at saturation are used (Figure 6). 


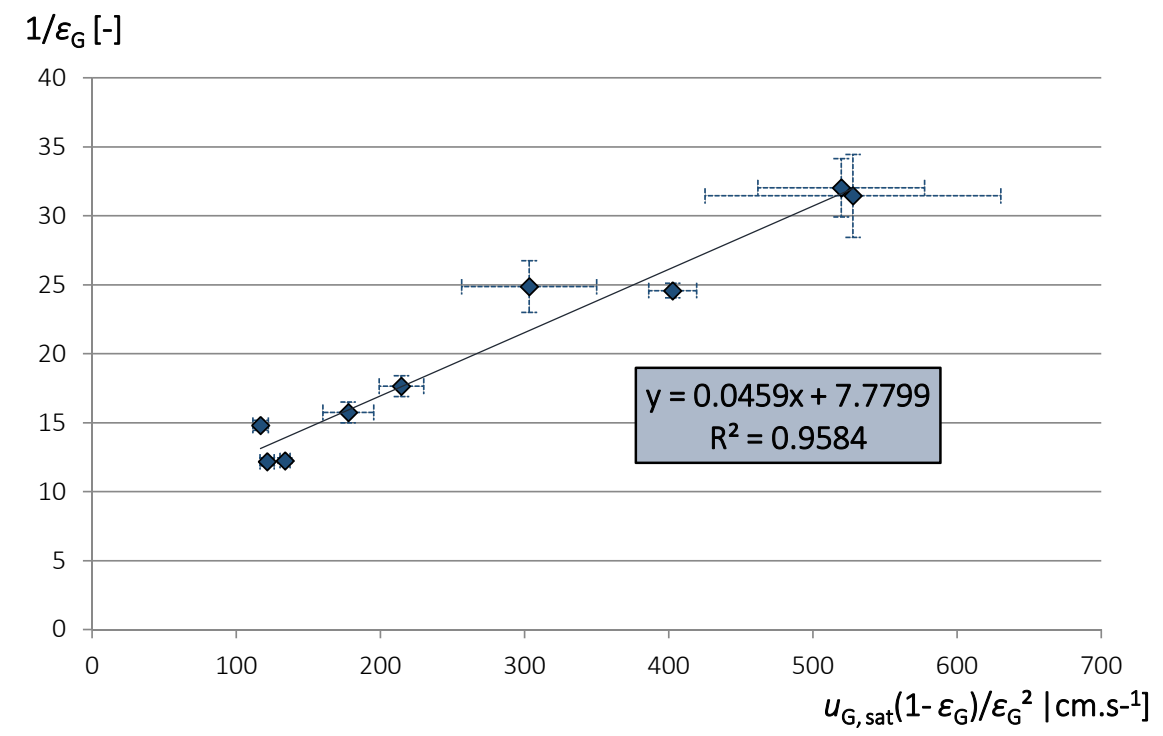

Figure 6: Ruzicka et al. (2001) model verification in homogeneous regime. Water-phenol system with $u_{G}>0,5 \mathrm{~cm} \cdot \mathrm{s}^{-1}$.

As for water/nitrogen system, the correlation only works at the highest superficial gas velocities $\left(\mathrm{u}_{\mathrm{G}}>\right.$ $0.5 \mathrm{~cm} . \mathrm{s}^{-1}$ ). Predictions of the equation of Ruzicka et al. (2001) are satisfactory, confirming that the regime is homogeneous. The regression parameters obtained in the case of the water-phenol system are $\zeta=6.8 \pm 1.2$ and $u_{B, \infty}=21.8 \pm 1.7 \mathrm{~cm} \cdot \mathrm{s}^{-1}$. This indicates on average a higher bubble density compared to water/nitrogen system and a slightly higher terminal velocity. Higher bubble density may indicate a decrease in bubble diameter. This is consistent with the effect of the presence of phenol previously described.

\section{Conclusion}

To conclude, the different systems studied agree and the effect of the phenol concentration is easily extrapolated for $\mathrm{x}=0$ (water/nitrogen system). The measurements obtained at $2 \mathrm{~g} \cdot \mathrm{L}^{-1}$, at 200, 230 and $240^{\circ} \mathrm{C}$ show that the differences between this system and pure water are not significant, given the uncertainty of the measurements made in pure water. The differences between the gas holdup increase with $\mathrm{u}_{\mathrm{G}}$ and with temperature, the measurements at $2 \mathrm{~g} \cdot \mathrm{L}^{-1}$ being situated in the high range of points obtained with nitrogen. The measurements at $10 \mathrm{~g} \cdot \mathrm{L}^{-1}$ at $200^{\circ} \mathrm{C}$ are also similar as those obtained 
in pure water, but still in the highest range of points obtained for water. On the other hand, the points at $240^{\circ} \mathrm{C}$ are much higher than those obtained in water, suggesting a positive effect of the presence of phenol at these temperatures. At $30 \mathrm{~g} \cdot \mathrm{L}^{-1}$ at 200,230 and $240^{\circ} \mathrm{C}$ the presence of phenol has a positive effect on gas holdup for $\mathrm{u}_{G}$, sat $>0.2 \mathrm{~cm} \cdot \mathrm{s}^{-1}$ compared to pure water. The point at $80 \mathrm{~g} \cdot \mathrm{L}^{-1}$ also confirms the positive effect of the presence of phenol at $100^{\circ} \mathrm{C}$. As for the prediction of the Ruzicka model for terminal velocities given the uncertainties $\left(21.8 \pm 1.7 \mathrm{~cm} \cdot \mathrm{s}^{-1}\right.$ for water-phenol system and $19.2 \pm 0.4$ $\mathrm{cm} . \mathrm{s}^{-1}$ for water system), it is possible to conclude that the values are actually identical. One the main result of this work is to show that the results obtained for an inert system (nitrogen/water) are coherent and can be used to determined the functioning of such gas liquid contactor when a waste (here modelled with phenol) is added. To extend the result, it would also be interesting to study triphasic system gas/liquid/solid in order to understand the influence of a particulate solid on the hydrodynamic characteristics.

All these elements are very important to better understand the behaviour of gas liquid contactors at high pressure and temperature and to improve the design of these contactors. One of the next challenge would be to find a simple model that take into account the influence of the different parameters, as shown in this paper, in order to help the understanding of gas liquid mass transfer in such conditions.

\section{References}

Lin, T.J., Juang, R.C., Chen., C.C., 2001. Characterizations of flow regime transitions in a high-pressure bubble column by chaotic time series analysis of pressure fluctuation signals, Chem. Eng. Sci. 56, 6241-6247.

Shaikh, A., Al-Dahhan, M., 2005. Characterization of the hydrodynamic flow regime in bubble columns via computed tomography, Flow Meas Instrum, 16, 91-98. 
Tarmy, B., Chang, M., Coulaloglou, C., Ponzi, P., 1984. Hydrodynamic characteristics of three phase reactors. Chem. Eng. 407, 18-23.

Wilkinson, P.M., Van Dierendonck, L.L., 1990. Pressure and gas density effects on bubble break-up and gas holdup in bubble columns. Chem. Eng. Sci. 45, 2309-2315.

Wilkinson, P.M., Spek, A.P., Van Dierendonck, L.L., 1992. Design parameters estimation for scale-up of highpressure bubble columns, AIChE J. 38, 544-554.

Lin, T.J., Tsuchiya, K., Fan, L.-S., 1998. Bubble flow characteristics in bubble columns at elevated pressure and temperature, AIChE J. 44, 545-560.

Schäfer, R. Merten C., Eigenberger G., 2002. Bubble size distributions in a bubble column reactor under industrial conditions, Exp. Therm Fluid Sci. 26, 595-604.

De Bruijn, T.J.W., Chase, J.D., Dawson, W.H., 1988. Gas holdup in a two-phase vertical tubular reactor at high pressure, Can. J. Chem. Eng. 66, 330-333.

Therning, P., Rasmuson, A., 2001. Liquid dispersion, gas holdup and frictional pressure drop in a packed bubble column at elevated pressures. Chem. Eng. J. 81, 331-335.

Idogawa, K., Ikeda, K., Fukuda, T., Morooka, S., 1986. Behavior of bubbles of the air-water system in a column under high pressure, Int. Chem. Eng. 26, 468-474.

Krishna, R., Wilkinson, P.M., Van Dierendonck, L.L., 1991. A model for gas holdup in bubble columns incorporating the influence of gas density on flow regime transitions, Chem. Eng. Sci. 46, 2491-2496.

Reilly, I.G., Scott, D.S., Debruijnand, T.J.W., Macintyre, D., 1994. The role of gas phase momentum in determining gas holdup and hydrodynamic flow regimes in bubble column operations, Can. J. Chem. Eng. 72, 3-12.

Clark, K.N., 1990. The effect of high pressure and temperature on phase distributions in a bubble column, Chem. Eng. Sci. 45, 2301-2307.

Kang, Y., Cho, Y.J. Woo K.J., Kim, S.D., 1999. Diagnosis of bubble distribution and mass transfer in pressurized bubble columns with viscous liquid medium, Chem. Eng. Sci. 54, 4887-4893. 
Kang, Y., Cho, Y.J., Woo, K.J., Kim, K.I., Kim, S.D., 2000. Bubble properties and pressure fluctuations in pressurized bubble columns, Chem. Eng. Sci. 55, 411-419.

Hashemi, S., Macchi, A., Servio, P., 2009. Gas-liquid mass transfer in a slurry bubble column operated at gas hydrate forming conditions, Chem. Eng. Sci. 64, 3709-3716.

Pjontek, D., Parisien, V., Macchi, A., 2014. Bubble characteristics measured using a monofibre optical probe in a bubble column and freeboard region under high gas holdup conditions, Chem. Eng. Sci. 111, 153-169

Oyevaar, M.H., Bos, R., Westerterp, K.R., 1991. Interfacial areas and gas hold-ups in gas-liquid contactors at elevated pressures from 0.1 to $8.0 \mathrm{MPa}$, Chem. Eng. Sci. 46, 1217-1231.

Jiang, P., Lin, T.J., Luo, X., Fan, L.-S., 1995. Flow visualization of high pressure (21 MPa) bubble column: bubble characteristics, Chem. Eng. Res. Des. 73, 269-274.

Leonard, C., Ferrasse, J.-H., Boutin, O., Lefevre, S., Viand, A., Measurements and correlations for gas liquid surface tension at high pressure and high temperature, AIChE Journal, https://doi.org/10.1002/aic.16216

Dewes, I., Schumpe, A., 1997. Gas density effect on mass transfer in the slurry bubble column. Chem. Eng. Sci. $52,4105-4109$

Krishna, R., Sie, S.T., 2000. Design and scale-up of the Fischer-Tropsch bubble column slurry reactor, Fuel Process. Technol. 64, 73-105

Ishibashi, H., Onozaki, M., Kobayashi, M., Hayashi, J.I., Itoh, H., Chiba, T., 2001. Gas holdup in slurry bubble column reactors of a $150 \mathrm{t} / \mathrm{d}$ coal liquefaction pilot plant process, Fuel 80, 655-664.

Chilekar, V.P., 2007. Hydrodynamics and mass transfer in slurry bubble columns: Scale and pressure effects. Eindhoven: Technische Universiteit Eindhoven DOI: 10.6100/IR6270232007.

Chilekar, V.P., van der Schaaf, J., Kuster, B.F.M., Tinge, J.T., Schouten, J.C., 2010. Influence of elevated pressure and particle lyophobicity on hydrodynamics and gas-liquid mass transfer in slurry bubble columns, AIChE J. 56, 584-596. 
Letzel, H.M., Schouten, J.C., van den Bleek, C.M., Krishna, R., 1997. Influence of elevated pressure on the stability of bubbly flows, Chem. Eng. Sci. 52, 3733-3739.

Letzel, H.M., Schouten, J.C., van den Bleek, C.M., Krishna, R., 1998. Effect of gas density on large-bubble holdup in bubble column reactors. AIChE J. 44, 2333-2336.

Letzel, H.M., Schouten, J.C., Krishna, R., van den Bleek, C.M., 1999. Gas holdup and mass transfer in bubble column reactors operated at elevated pressure, Chem. Eng. Sci. 54, 2237-2246.

Kemoun, A., Cheng Ong, B., Gupta, P., Al-Dahhan, M.H., Dudukovic, M.P., 2001. Gas holdup in bubble columns at elevated pressure via computed tomography, Int. J. Multiphase Flow 27, 929-946.

Kumar, S., Munshi, P., Khanna, A., 2012. High Pressure Experiments and Simulations in Cocurrent Bubble Columns. Procedia Engineering, 42, 842-853.

Pohorecki, R., Moniuk, W., Zdrójkowski, A., 1999. Hydrodynamics of a bubble column under elevated pressure, Chem. Eng. Sci. 54, 5187-5193.

Sangnimnuan, A., Prasad, G.N., Agnew, J.B., 1984. Gas hold-up and backmixing in a bubble-column reactor under coal-hydroliquefaction conditions, Chem. Eng. Commun 25, 193-212.

Krishna, R., Ellenberger, J., 1996. Gas holdup in bubble column reactors operating in the churn-turbulent flow regime, AIChE J. 42, 2627-2634.

Jordan, U., Schumpe, A., 2001. The gas density effect on mass transfer in bubble columns with organic liquids, Chem. Eng. Sci. 56, 6267-6272.

Lorenz, O., Schumpe, A., Ekambara, K., Joshi, J.B., 2005. Liquid phase axial mixing in bubble columns operated at high pressures, Chem. Eng. Sci. 60, 3573-3586.

Behkish, A., Lemoine, R., Sehabiague, L., Oukaciand, R., Morsi, B.I., 2007. Gas holdup and bubble size behavior in a large-scale slurry bubble column reactor operating with an organic liquid under elevated pressures and temperatures, Chem. Eng. J. 128, 69-84. 
Lau, R., Peng, W., Velazquez-Vargas, L.G., Yang, G.Q., Fan, L.-S., 2004. Gas-Liquid Mass Transfer in High-Pressure Bubble Columns, Ind. Eng. Chem. Res. 43, 1302-1311.

Lefèvre, S., Boutin, O., Ferrasse, J-H., Malleret, L., Faucherand, R., Viand, A.,2011, Thermodynamic and kinetic study of phenol degradation by a non-catalytic wet air oxidation process, Chemosphere, 84, 1208-1215.

Luo, X. Lee, D.J., Lau, R., Yang, G., Fan, L.-S., 1999. Maximum stable bubble size and gas holdup in high-pressure slurry bubble columns AIChE J. 45, 665-680.

Soong, Y., Harke, F.W., Gamwo, I.K., Schehl, R.R., Zarochak, M.F., 1997. Hydrodynamic study in a slurry-bubblecolumn reactor, Catal. Today 35, 427-434.

Ishiyama, H., Isokawa, Y., Sawaiand, J., Kojima, H., 2001. Hydrodynamics in a small size pressurized bubble column, Chem. Eng. Sci. 56, 6273-6278.

Deckwer, W.-D., Louisi, L., Zaidi, A., Ralek, M., 1980. Hydrodynamic Properties of the Fischer-Tropsch Slurry Process. Ind. Eng. Chem. Proc. Des. Dev. 19, 699-708.

Kölbel, H., Klötzer, D., Hammer, H., 1971. Zur Reaktionstechnik von Blasensäulen-Reaktoren mit suspendiertem Katalysator bei erhöhtem Druck, Chemie Ingenieur Technik 43, 103-111.

Yang, W., Wang, J., Jin, Y., 2001. Mass Transfer Characteristics of Syngas Components in Slurry System at Industrial Conditions, Chem. Eng. Technol. 24, 651-657.

Grover, G.S., Rode, C.V., Chaudhari, R.V., 1986. Effect of temperature on flow regimes and gas hold-up in a bubble column. Can. J. Chem. Eng. 64, 501-504.

Biń, A.K., Duczmal, B., Machniewski, P., 2001. Hydrodynamics and ozone mass transfer in a tall bubble column, Chem. Eng. Sci. 56, 6233-6240.

Jin, H., Yang, S., He, G., Wang, M., Williams, R.A., 2010. The effect of gas-liquid counter-current operation on gas hold-up in bubble columns using electrical resistance tomography, J. Chem. Technol. Biotechnol. 85, 1278-1283. Kluytmans, J.H.J., Van Wachem, B.G.M., Kuster, B.F.M., Schouten, J.C., 2003. Mass transfer in sparged and stirred reactors: influence of carbon particles and electrolyte, Chem. Eng. Sci. 58, 4719-4728. 
Fukuma, M., Muroyamaand, K., Yasunishi, A., 1987. Properties of bubbles swarm in a slurry bubble column, J. Chem. Eng. Jpn. 20, 28-33.

Smith, J.S., Burns, L.F., Valsaraj, K.T., Thibodeaux, L.J., 1996. Bubble Column Reactors for Wastewater Treatment. 2. The Effect of Sparger Design on Sublation Column Hydrodynamics in the Homogeneous Flow Regime, Ind. Eng. Chem. Res. 35, 1700-1710.

Xue, J., Al-Dahhan, M.H., Dudukovic, M.P., Mudde, R.F., 2008. Bubble velocity, size, and interfacial area measurements in a bubble column by four-point optical probe, AIChE J. 54, 350-363.

Simonnet, M., Gentric, C., Olmos, E., Midoux, N., 2007. Experimental determination of the drag coefficient in a swarm of bubbles, Chem. Eng. Sci. 62, 858-866.

Majumder, S.K., Kundu, G., Mukherjee, D., 2006. Bubble size distribution and gas-liquid interfacial area in a modified downflow bubble column, Chem. Eng. J. 122, 1-10.

Muroyama, K., Imai, K., Oka, Y., Hayashi, J.I., 2013. Mass transfer properties in a bubble column associated with micro-bubble dispersions, Chem. Eng. Sci. 100, 464-473.

García-Abuín, A., Gómez-Díaz, D., Losada, M., Navaza, J.M., 2012. Bubble column gas-liquid interfacial area in a polymer+surfactant+water system, Chem. Eng. Sci. 75, 334-341.

Zahradník, J., Fialová, M., Růžička, M., Drahoš, J., Kaštánek, F., Thomas, N.H., 1997. Duality of the gas-liquid flow regimes in bubble column reactors. Chem. Eng. Sci. 52, 3811-3826.

Reilly, I.G., Scott, D.S., De Bruijn, T., Jain, A., Piskorz, J., 1986, A correlation for gas holdup in turbulent coalescing bubble columns, Can. J. Chem. Eng. 64, 705-717.

Ohki, Y., Inoue, H., 1970. Longitudinal mixing of the liquid phase in bubble columns, Chem. Eng. Sci. 25, 1-16.

Kantarci, N., Borak, F., Ulgen, K.O., 2005. Bubble column reactors, Process Biochemistry, 40, 2263-2283.

Bouaifi, M., Hebrard, G., Bastoul, D., Roustan, M.A, 2001. Comparative study of gas hold-up, bubble size, interfacial area and mass transfer coefficients in stirred gas-liquid reactors and bubble columns. Chem. Eng. Process 40, 97-111. 
Ruzicka, M.C., Drahoš, J., Fialová, M., Thomas, N.H., 2001. Effect of bubble column dimensions on flow regime transition, Chem. Eng. Sci. 56, 6117-6124.

Parasu Veera, U., Joshi, J.B., 2000. Measurement of gas hold-up profiles in bubble column by gamma ray tomography: effect of liquid phase properties, Chem. Eng. Res. Des. 78, 425-434.

Forret, A., Schweitzer, J.M., Gauthier, T., Krishna, R., Schweich, D., 2003. Influence of scale on the hydrodynamics of bubble column reactors: an experimental study in columns of 0.1, 0.4 and $1 \mathrm{~m}$ diameter, Chem. Eng. Sci. 58, 719-724.

Yang, G.Q., Fan, L.-S., 2003. Axial liquid mixing in high-pressure bubble columns, AIChE J. 49, 1995-2008.

Chaumat, H., Billet-Duquenne, A.-M., Augier, F., Mathieu, C., Delmas, H., 2005. Mass transfer in bubble column for industrial conditions-effects of organic medium, gas and liquid flow rates and column design, Chem. Eng. Sci. 60, 5930-5936.

Jin, H., Yang, S., Wang, M., Williams, R.A., 2007. Measurement of gas holdup profiles in a gas liquid cocurrent bubble column using electrical resistance tomography, Flow Measurement and Instrumentation, 18, 191-196.

Shah, M., Kiss, A.A., Zondervan, E., van der Schaaf, J., De Haan, A.B., 2012. Gas holdup, axial dispersion, and mass transfer studies in bubble columns, Ind. Eng. Chem. Res. 51, 14268-14278.

Hikita, H., Kikukawa, H., 1974. Liquid-phase mixing in bubble columns: Effect of liquid properties, Chem. Eng. J. 8, 191-197.

Boyer, C., Duquenne, A.-M., Wild, G., 2002. Measuring techniques in gas-liquid and gas-liquid-solid reactors, Chem. Eng. Sci. 57, 3185-3215.

Tang, C., Heindel, T.J., 2006. Estimating gas holdup via pressure difference measurements in a cocurrent bubble column, Int. J. Multiphase Flow, 32, 850-863.

Han, L., Al-Dahhan, M.H., 2007. Gas-liquid mass transfer in a high pressure bubble column reactor with different sparger designs, Chem. Eng. Sci. 62, 131-139.

Wallis, G.B., 1969. One Dimensional Two Phase Flow, McGraw Hill, New York. 
Zuber, N., Findlay, J.A., 1965. Average volumetric concentration in two-phase flow systems, J. Heat Transfer, 87, $453-468$

Ruzicka, M.C., Zahradník, J., Drahoš, J., Thomas, N.H., 2001. Homogeneous-heterogeneous regime transition in bubble columns, Chem. Eng. Sci. 56 (2001) 4609-4626.

Benjamin, T.B., 1986. Note on added mass and drift, J. Fluid Mech. 169, 251-256.

Baz-Rodríguez, S.A., Botello-Alvarez, J.E., Estrada-Baltazar, A., Vilchiz-Bravo, L.E., Padilla-Medina, J.A., MirandaLópez, R., 2014. Effect of electrolytes in aqueous solutions on oxygen transfer in gas-liquid bubble columns, Chem. Eng. Res. Des., 92, 2352-2360.

Himmelblau, D.M., 1960. Solubilities of inert gases in water. $0^{\circ} \mathrm{C}$. to near the critical point of water, J. Chem. Eng. Data 5, 10-15. 


\section{Appendix A Validation of the assumptions on the pressure}

Among the various correlations available for the prediction of the two-phase friction losses, Whalley and Hewitt (1978) propose using the ratio of the viscosities of liquid and gas as a criterion. In this study, this ratio is comprised in the range 3.8-12.6. The correlation of Friedel (1979) is recommended for these conditions (equation A1, explained with equations A2 to A10). However, it is not very precise since it has a standard deviation of $50 \%$ for two-phase flows. However, it allows the estimation of the order of magnitude of the frictional pressure loss.

$$
\begin{aligned}
& \Phi_{L 0}^{2}=C_{1}+\frac{3,43 C_{2} C_{3}}{\dot{F} r_{L}^{0,047} W e^{0,0334}} \\
& \Phi_{L 0}^{2}=\frac{\left|\frac{d P}{d z}\right|_{f}}{\frac{-4 \dot{m} C_{f L 0}}{\rho_{L} D_{C}}}
\end{aligned}
$$

$\Phi_{L 0}^{2}$ is the two-phase multiplier of Chisholm.

$$
\begin{aligned}
& \mathrm{C}_{1}=(1-\chi)^{2}+\chi^{2} \frac{\rho_{L}}{\rho_{G}} \frac{C_{f G 0}}{C_{f L 0}} \\
& \mathrm{C}_{2}=\chi^{0,685}(1-\chi)^{0,24} \\
& \mathrm{C}_{3}=\left(\frac{\rho_{L}}{\rho_{G}}\right)^{0,8}\left(\frac{\mu_{G}}{\mu_{L}}\right)^{0,22}\left(1-\frac{\mu_{G}}{\mu_{L}}\right)^{0,89} \\
& \dot{F} r_{L}=\frac{\dot{m}^{2}}{\rho_{X}^{2} g D_{C}} \\
& \dot{W} e=\frac{\dot{m}^{2} D_{C}}{\rho_{X} \sigma_{L}} \\
& \dot{m}=\frac{m^{\prime}{ }_{G}+m_{L}^{\prime}}{S_{C}} \\
& \chi=\frac{m_{G}^{\prime}}{S_{C} \dot{m}} \\
& \frac{1}{\rho_{X}}=\frac{\chi}{\rho_{G}}+\frac{1-\chi}{\rho_{L}}
\end{aligned}
$$


The friction coefficients $C_{f L 0}$ et $C_{f G 0}$ notés $C_{f K 0}$ are calculated with equations A11 and A12.

$$
\begin{aligned}
& \dot{R} e_{K}=\frac{\dot{m} D_{C}}{\mu_{K}}<1055, C_{f K 0}=\frac{8}{\dot{R} e_{K}} \\
& \dot{R} e_{K}=\frac{\dot{m} D_{C}}{\mu_{K}}>1055, C_{f K 0}=\left[2,4567 \ln \frac{\dot{R} e_{K}}{1,964 \ln \dot{R} e_{K}-3,8215}\right]^{-2}
\end{aligned}
$$

The results of the calculation show that the frictional head loss is higher at $10 \mathrm{MPa}$ and $100^{\circ} \mathrm{C}$ under the conditions studied. It decreases when the temperature increases (the viscosity decreases) and when the pressure increases (effect of gas density). The value of the maximum pressure loss calculated by the Friedel correlation is $8.89 .10-2 \mathrm{~Pa}$. If a $50 \%$ error on the maximum value is considered, it is not more than $0.18 \mathrm{~Pa}$. This is clearly negligible compared to the static pressure drop. This conclusion is consistent with the results of Tang and Heindel (2006) for the range of superficial gas and liquid velocities and the liquid system used in this study.

\section{Appendix B Effects of liquid evaporation and gas solubility.}

At high pressures and temperatures, gas solubility (nitrogen and oxygen) is not negligible. Similarly, at the temperatures studied, the evaporation of the liquid can be significant. For example, at $250^{\circ} \mathrm{C}$, the partial pressure of the water in the gas phase under saturated conditions is $3.98 \mathrm{MPa}$ (Lorenz et al., 2004).

\section{Quantification of the evaporation effects of water}

If it is assumed that the gas is fully saturated at the column outlet, the volumetric flowrate of water vapor is obtained from equation B1. From this value it is then possible to calculate the superficial gas velocity under saturated conditions.

$$
\mathrm{Q}_{\mathrm{V}, \mathrm{vap}}=\frac{\mathrm{y}_{\mathrm{v}, \mathrm{H} 2 \mathrm{O}}}{1-\mathrm{y}_{\mathrm{v}, \mathrm{H} 2 \mathrm{O}}} \mathrm{Q}_{\mathrm{V}, \mathrm{N} 2}
$$


From equation $\mathrm{A} 13$ and using the water vapor density values from the NIST website, the mass flowrate of water vapor can be estimated. The evaporation rate (mass flowrate of evaporated water / input water mass flowrate) obtained depends on the mass ratio of gas and liquid at the reactor inlet, pressure and temperature. The results are shown in Figure B1. The nature of the gas used (air or nitrogen) has no influence on the rate of evaporation of the liquid at saturation.

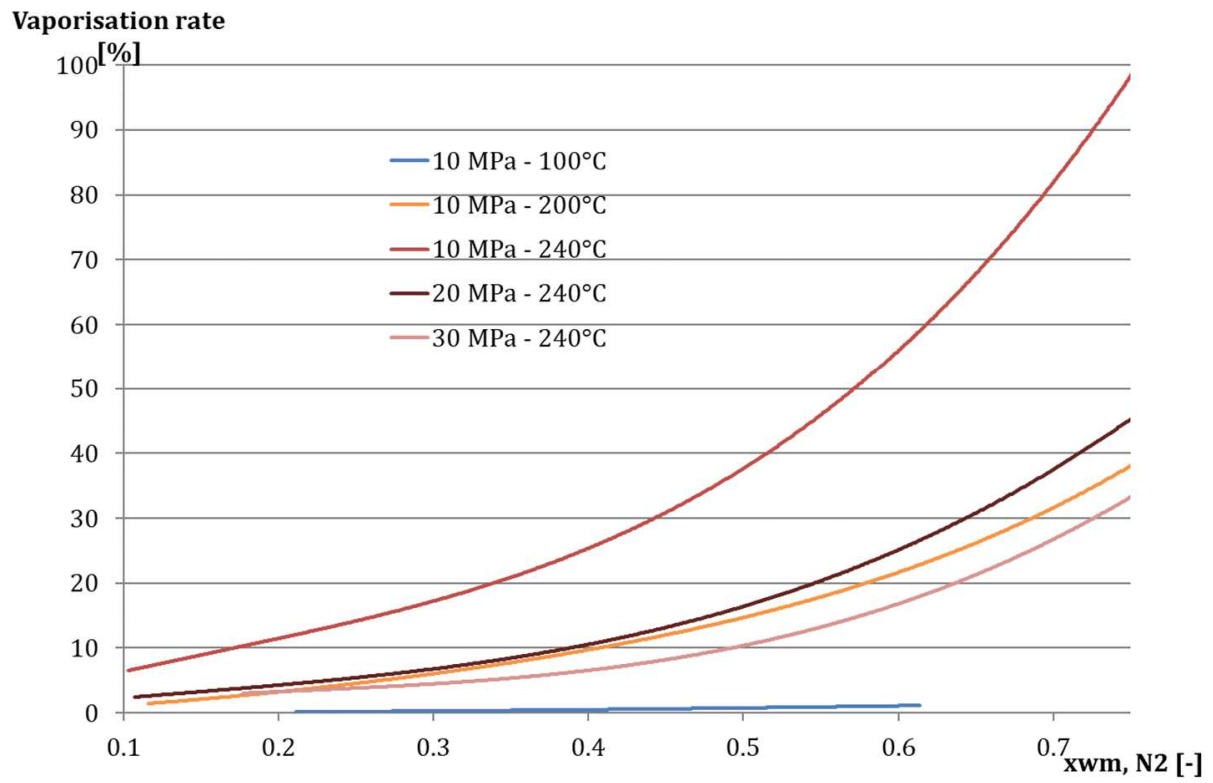

Figure B1: Theoretical vaporisation rate as a function of the gas mass fraction at the inlet of the reactor.

The results show that evaporation decreases with pressure. It obviously increases with temperature and with the input gas mass fraction. Evaporation is almost never negligible, except at pressures greater than or equal to $20 \mathrm{MPa}$, at temperatures below $200^{\circ} \mathrm{C}$ and for $\mathrm{x}_{\mathrm{wm}}, \mathrm{N}_{2}$ less than 0.3 . For all other conditions, evaporation is important and even leads to complete evaporation under the most unfavourable conditions, for input mass fractions higher than 0.7 at $10 \mathrm{MPa}$ and $240^{\circ} \mathrm{C}$. Evaporation, even if incomplete, can have significant effects on the density of the gas. To quantify this effect, calculations were made considering the saturated water at the column outlet and calculating the density. Density variations between dry gas and saturated gas are shown in Figure B2. 


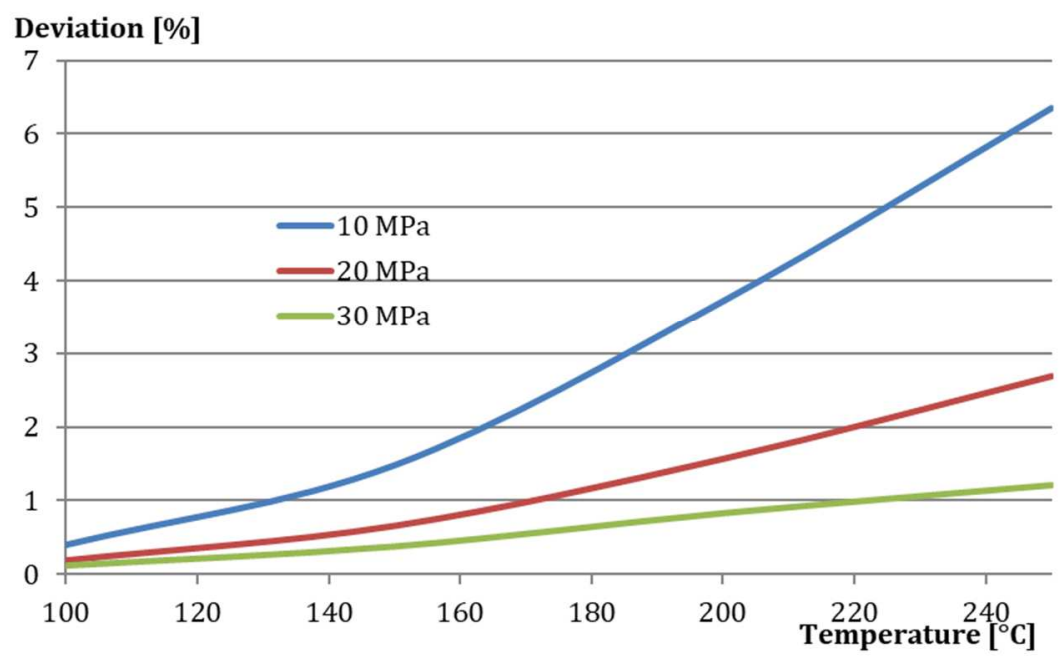

Figure B2: Differences between gas density in dry and saturated conditions.

Deviations are mostly negligible, except at $10 \mathrm{MPa}$ for temperatures above $180^{\circ} \mathrm{C}$. The influence of this effect on the calculation of gas holdup should be tested. For tests performed at $10 \mathrm{MPa}$ and $240^{\circ} \mathrm{C}$, a decrease in gas density of the order of $6 \%$ leads to a difference of only $1.7 \%$ in gas holdup (at $20 \mathrm{MPa}$ and $240^{\circ} \mathrm{C}$ at low flow rate with a gas density difference of $2.5 \%$ : $0.5 \%$ at $10 \mathrm{MPa}$ and $100^{\circ} \mathrm{C}: 0.12 \%$ ). For the water-phenol/air system, the influence of the chemical reaction on the density of the gas is considered by a material balance. The real density of the gas is then used in equation 8 . Phase equilibrium calculations show that the composition of the gas under saturation conditions is almost identical for the water-phenol/nitrogen system and for the water/nitrogen system. In conclusion, the influence of saturation on gas density for the water-phenol/air and water-phenol/nitrogen systems is similar to the one on the water/nitrogen system.

Quantification of the effects of gases solubility

The gas loss can be significant when the liquid is initially saturated with air, with a concentration of oxygen and dissolved nitrogen corresponding to a solubility at $0.5 \mathrm{MPa}$ and $25^{\circ} \mathrm{C}$ maximum (pressure and temperature of the charge tank). The Henry's constant of nitrogen can also be estimated by the Himmelblau correlation (Himmelblau, 1960). The calculation of the solubility of nitrogen is done using 
the partial pressure of nitrogen in the gas phase. For pure nitrogen, solubility may be important. Considering an input / output molar balance on the nitrogen in the gas and liquid phase and the molar flow of nitrogen in the liquid phase corresponding to a concentration equal to its solubility (without evaporation), it is possible to evaluate the maximum nitrogen losses in the gas phase. For this calculation, a gas phase consisting of pure nitrogen is considered. The density of the gas is considered constant (no evaporation). The mass losses of nitrogen correspond then to the losses in superficial velocity. Since the losses are maximum at high pressure (higher solubility) and at high liquid flow, the results at $30 \mathrm{MPa}$ and $100 \mathrm{~g} \cdot \mathrm{min}^{-1}$ are shown in Figure B3.

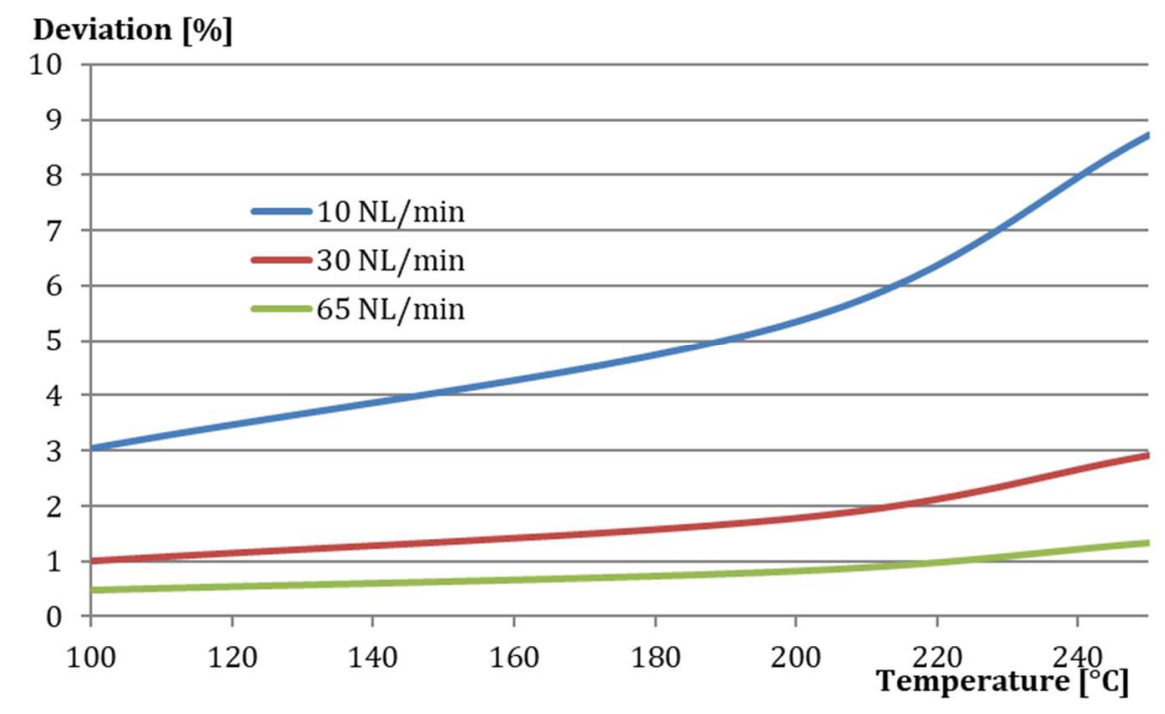

Figure B3: Maximum variations of superficial velocity $\boldsymbol{Q}_{G}{ }^{\circ} . P=30 \mathrm{MPa}, \boldsymbol{Q}_{L}{ }^{\circ}=100 \mathrm{~g} \cdot \mathrm{min}^{-1}$

Losses due to solubility variations increase with temperature. They are negligible at rates higher than 30NL.min ${ }^{-1}$. On the other hand, they can be important at $10 \mathrm{NL} \cdot \mathrm{min}^{-1}$ for temperatures higher than $190^{\circ} \mathrm{C}$. It is not necessary to work at a lower rate for which the losses become significant.

The solubilization of the gas can influence the density of the liquid. Given the significant solubility of the gas in the liquid, it may be interesting to estimate the maximum variations in liquid density. The completely saturated liquid is considered at the outlet of the column. The density of the gas saturated liquid can be estimated with equation B2. 


$$
\rho_{L, s a t}=\left(1-x_{v, H 2 O}\right) \rho_{N 2}+x_{v, H 2 O} \rho_{H 2 O}
$$

The volumetric fractions of water and nitrogen are estimated from the mole fraction of nitrogen. The results show a slight change in the density of the liquid with the amount of dissolved nitrogen, as shown in Figure B4.

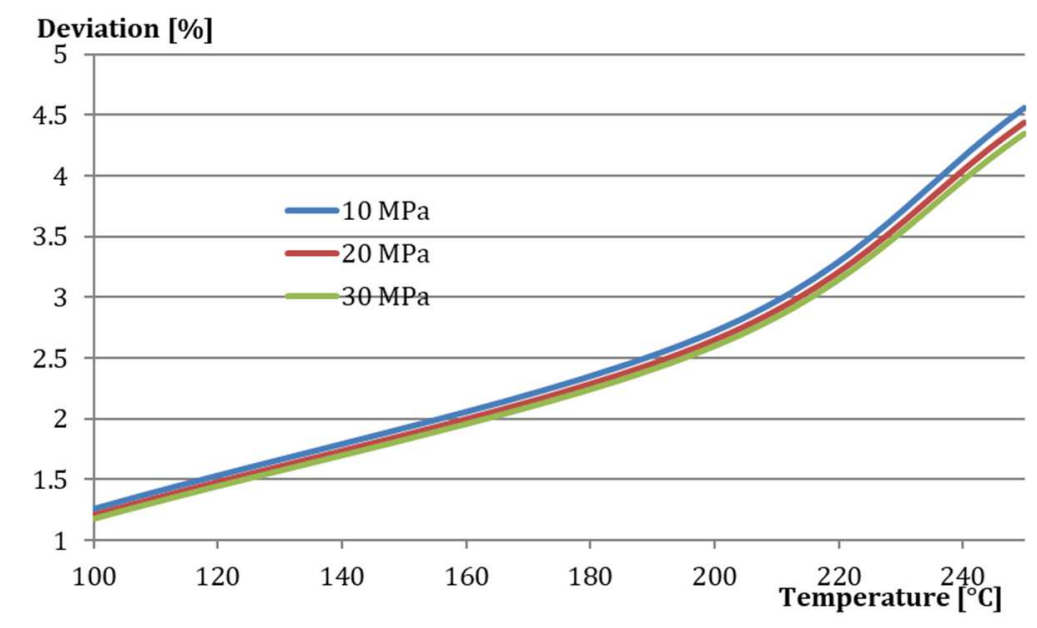

Figure B4: Density differences between water and saturated liquid.

Deviation depends little on pressure but increase with temperature. As for the density of the gas, it is possible to evaluate the effect on the holdup calculation. If one considers the density of the saturated liquid for both the zero and the value considered, the differences obtained remain relatively low. This gives a difference of about $1.5 \%$ for tests at $100^{\circ} \mathrm{C}$, deviations of about $3.5 \%$ for tests at $200^{\circ} \mathrm{C}$. At $240^{\circ} \mathrm{C}$, the differences can be significant and in the order of $5.5 \%$. The holdup calculation is therefore sensitive to the density of the liquid. It is advisable to take an average density between saturated and unsaturated, which leads to errors of up to $3.5 \%$ at $240^{\circ} \mathrm{C}$. It is indeed difficult to know a priori the degree of saturation without $\mathrm{k}_{\llcorner} \mathrm{a}$ values. 


\section{Appendix C: Pressure losses though acceleration}

The two-phases steady-state flow model, assuming interfacial continuity, leads to momentum balances for the gas phase (equation C1) and the liquid phase (equation C2).

$$
\begin{aligned}
& \frac{1}{\mathrm{~S}_{\mathrm{C}}} \frac{\partial\left(\rho_{\mathrm{G}} \frac{\mathrm{u}_{\mathrm{G}}{ }^{2}}{\left.\varepsilon_{\mathrm{G}} \mathrm{S}_{\mathrm{C}}\right)}\right.}{\partial \mathrm{z}}=-\varepsilon_{\mathrm{G}} \frac{\partial \mathrm{P}}{\partial \mathrm{z}}-\rho_{\mathrm{G}} \mathrm{g} \varepsilon_{\mathrm{G}}-\frac{\Theta_{\mathrm{P}, \mathrm{G}} \mathrm{h}_{\mathrm{G}}}{\mathrm{S}_{\mathrm{C}}}-\Theta_{\mathrm{i}} \mathrm{a}+\frac{\mathrm{S}_{\mathrm{i}} \mathrm{u}_{\mathrm{i}}}{\mathrm{S}_{\mathrm{C}}} \\
& \frac{1}{\mathrm{~S}_{\mathrm{C}}} \frac{\partial\left(\rho_{\mathrm{L}} \frac{\mathrm{u}_{\mathrm{L}}{ }^{2}}{\left(1-\varepsilon_{\mathrm{G}}\right)} \mathrm{S}_{\mathrm{C}}\right)}{\partial \mathrm{z}}=-\left(1-\varepsilon_{\mathrm{G}}\right) \frac{\partial \mathrm{P}}{\partial \mathrm{z}}-\rho_{\mathrm{L}} \mathrm{g}\left(1-\varepsilon_{\mathrm{G}}\right)-\frac{\Theta_{\mathrm{P}, \mathrm{L}} \mathrm{h}_{\mathrm{L}}}{\mathrm{S}_{\mathrm{C}}}+\Theta_{\mathrm{i}} \mathrm{a}-\frac{\mathrm{S}_{\mathrm{i}} \mathrm{u}_{\mathrm{i}}}{\mathrm{S}_{\mathrm{C}}}
\end{aligned}
$$

By combining equations $C 1$ and $C 2$ (and assuming negligible wall stresses $\Theta_{P, G}=\Theta_{P, L}=0$ ) and a constant section in the column, equation C3 is obtained. The hypothesis of negligible wall stresses is validated in the case where friction losses are negligible. This point has already been discussed previously.

$$
\frac{\partial\left(\rho_{\mathrm{L}} \frac{\mathrm{u}_{\mathrm{L}}{ }^{2}}{\left(1-\varepsilon_{\mathrm{G}}\right)}+\rho_{\mathrm{G}} \frac{\mathrm{u}_{\mathrm{G}}{ }^{2}}{\varepsilon_{\mathrm{G}}}\right)}{\partial \mathrm{z}}=-\frac{\partial \mathrm{P}}{\partial \mathrm{z}}-\mathrm{g}\left[\rho_{\mathrm{L}}\left(1-\varepsilon_{\mathrm{G}}\right)+\rho_{\mathrm{G}} \varepsilon_{\mathrm{G}}\right]
$$

Equation C3 leads to the static pressure drop in the column by neglecting the term to the left of equality (fluid acceleration). Assuming a linear evolution of the terms $\rho_{\mathrm{L}} \frac{\mathrm{u}_{\mathrm{L}}{ }^{2}}{\left(1-\varepsilon_{\mathrm{G}}\right)}$ and $\rho_{\mathrm{G}} \frac{\mathrm{u}_{\mathrm{G}}{ }^{2}}{\varepsilon_{\mathrm{G}}}$ along the column, an approximate calculation to evaluate this variation is possible. The slope of the line is given by the difference between the values of these terms at the output and the column entry divided by the height.

For calculation a loss of gas by solubility of around $10 \%$ at the end of column is considered as well as a loss of water by evaporation of $50 \%$. The densities of nitrogen and water are used for calculation. A linear evolution of the gas holdup with the superficial gas velocity is assumed. Under these conditions the left-hand term of the equality in equation C3 can be evaluated by equation C4.

$$
\frac{\partial\left(\rho_{\mathrm{L}} \frac{\mathrm{u}_{\mathrm{L}}{ }^{2}}{\left(1-\varepsilon_{\mathrm{G}}\right)}+\rho_{\mathrm{G}} \frac{\mathrm{u}_{\mathrm{G}}{ }^{2}}{\varepsilon_{\mathrm{G}}}\right)}{\partial \mathrm{z}} \approx \frac{\left[\rho_{\mathrm{L}} \frac{\mathrm{u}_{\mathrm{L}}{ }^{2}}{\left(1-\varepsilon_{\mathrm{G}}\right)}\right]_{\mathrm{S}}-\left[\rho_{\mathrm{L}} \frac{\mathrm{u}_{\mathrm{L}}{ }^{2}}{\left(1-\varepsilon_{\mathrm{G}}\right)}\right]_{\mathrm{E}}}{\Delta \mathrm{z}}+\frac{\left[\rho_{\mathrm{G}} \frac{\mathrm{u}_{\mathrm{G}}{ }^{2}}{\varepsilon_{\mathrm{G}}}\right]_{\mathrm{S}}-\left[\rho_{\mathrm{G}} \frac{\mathrm{u}_{\mathrm{G}}{ }^{2}}{\varepsilon_{\mathrm{G}}}\right]_{\mathrm{E}}}{\Delta \mathrm{z}}
$$


Since holdup is at the denominator, a low value is chosen to obtain the highest pressure loss through acceleration (0.02). A variation of the water densities of $5 \%$ is considered, (which decreases because of the dissolved gas) and $8 \%$ for the gas, which decreases because of the evaporation. The calculation shows that the left term of equation $\mathrm{C} 4$ is maximum at low pressure (10MPa) at high temperature $\left(250^{\circ} \mathrm{C}\right)$, at high gas flow $\left(65 \mathrm{NL} \cdot \mathrm{min}^{-1}\right)$ and at low liquid flow $\left(25 \mathrm{~g} \cdot \mathrm{min}^{-1}\right)$. The maximum value obtained is $0.28 \mathrm{~Pa}$. Considering only the loss by solubility $(10 \%)$ the value obtained is $0.30 \mathrm{~Pa}$, indicating a weak influence of evaporation on this calculation, mainly because the superficial velocity of liquid is an order of magnitude less than the gas one. For holdups between 0.1 and 0.2 , the value becomes lower and of the order of $2 \cdot 3 \cdot 10^{-2} \mathrm{~Pa}$. The variations are therefore clearly negligible.

By combining the variations obtained for friction and acceleration pressure losses, the maximum uncertainty obtained is approximately $0.4 \mathrm{~Pa}$. This value is low. Moreover, this value is probably overestimated because the maxima are not obtained under the same conditions. 


\section{Appendix D: Gas hold up in function of temperature at different pressures}

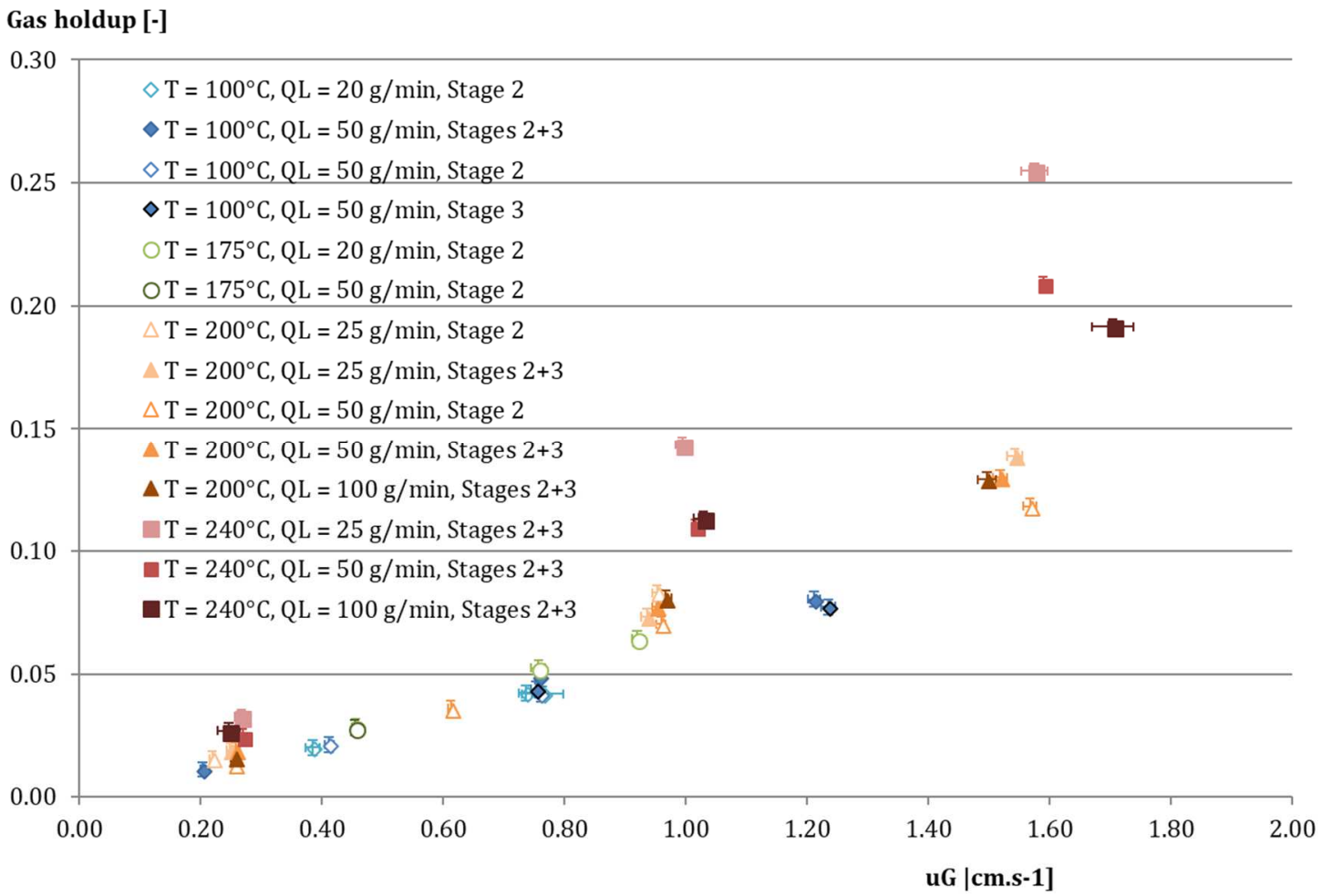

Figure D1: Gas hold up measurements, for water/nitrogen system, at $\mathrm{P}=10 \mathrm{MPa}$. Empty symbols: measurements in the $2^{\text {nd }}$ stage. Full symbols: measurements in $2^{\text {nd }}$ and $3^{\text {rd }}$ stages. Symbols with dark outlines: measurements in the $3^{\text {rd }}$ stage. Colour gradients: liquid flow intensity. 


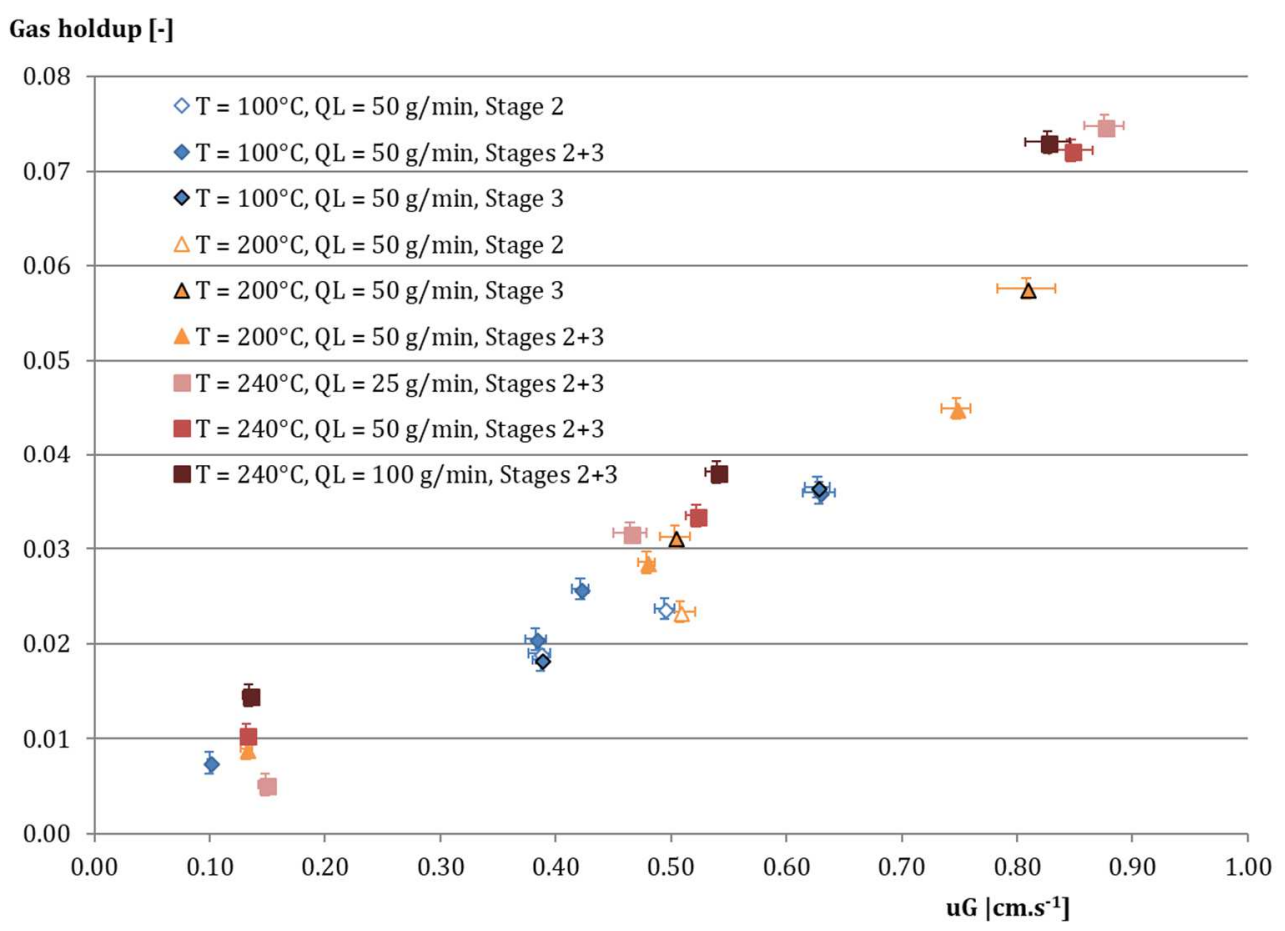

Figure D2: Gas hold up measurements, for water/nitrogen system, at $P=20 \mathrm{MPa}$. Empty symbols: measurements in the $2^{\text {nd }}$ stage. Full symbols: measurements in $2^{\text {nd }}$ and $3^{\text {rd }}$ stages. Symbols with dark outlines: measurements in the $3^{\text {rd }}$ stage. Colour gradients: liquid flow intensity.

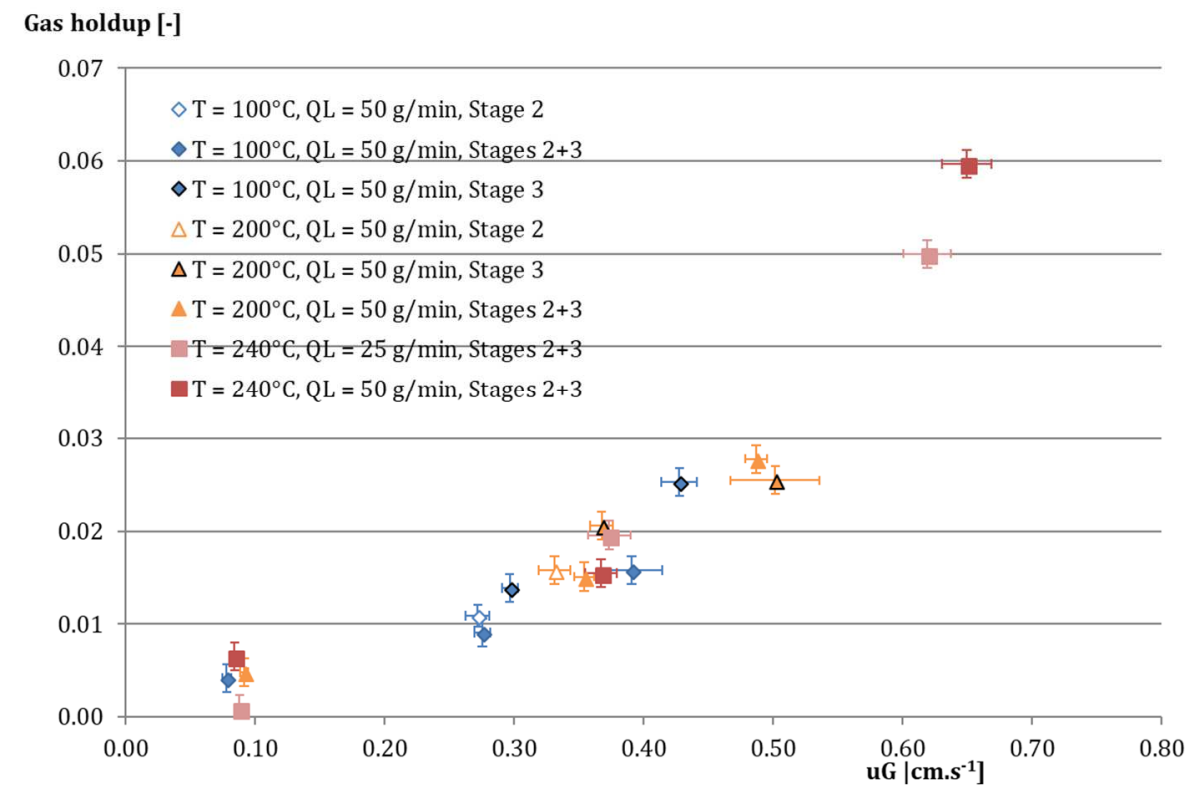

Figure D3: Gas hold up measurements, for water/nitrogen system, at $P=30 \mathrm{MPa}$. Empty symbols: measurements in the $2^{\text {nd }}$ stage. Full symbols: measurements in $2^{\text {nd }}$ and $3^{\text {rd }}$ stages. Symbols with dark outlines: measurements in the $3^{\text {rd }}$ stage. Colour gradients: liquid flow intensity. 


\section{Appendix E: Gas holdup versus pressure at different temperatures}

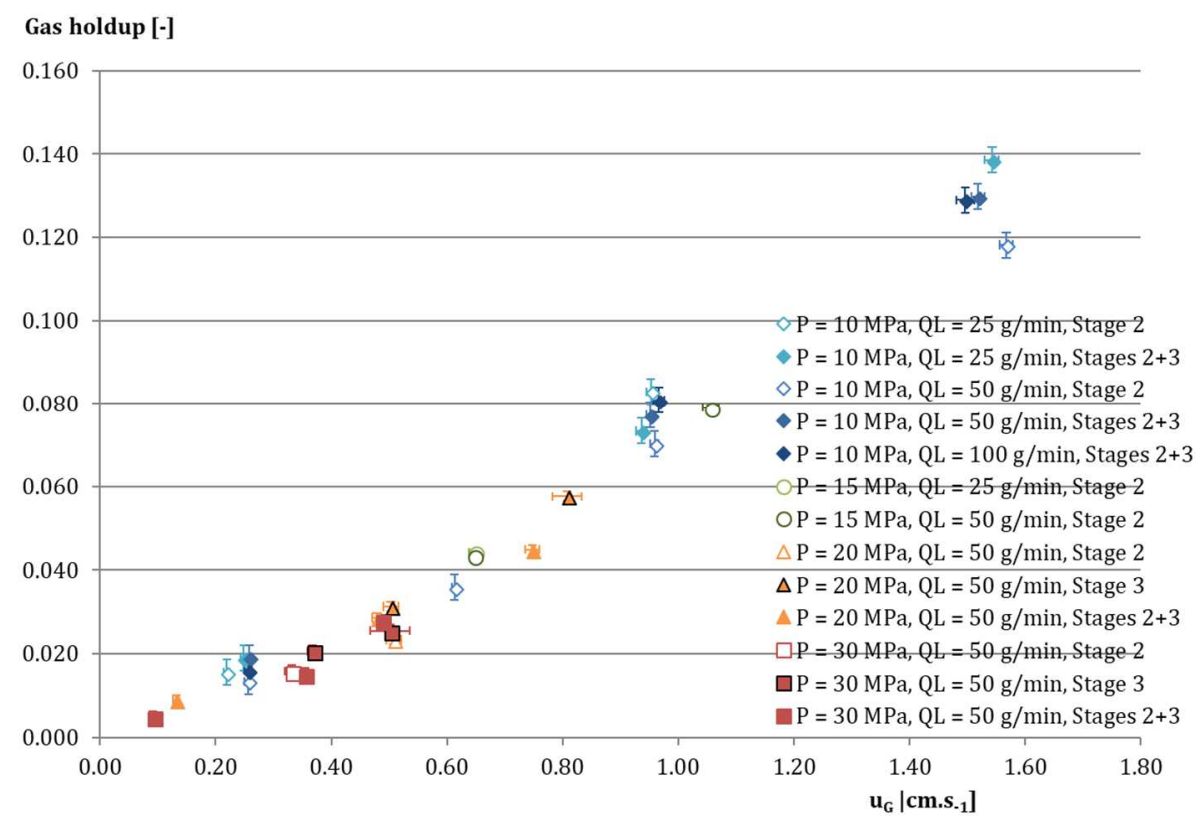

Figure E1: Gas hold up measurements, for water/nitrogen system, at $T=200^{\circ} \mathrm{C}$. Empty symbols: measurements in the $2^{\text {nd }}$

stage. Full symbols: measurements in $2^{\text {nd }}$ and $3^{\text {rd }}$ stages. Symbols with dark outlines: measurements in the $3^{\text {rd }}$ stage. Colour gradients: liquid flow intensity. 


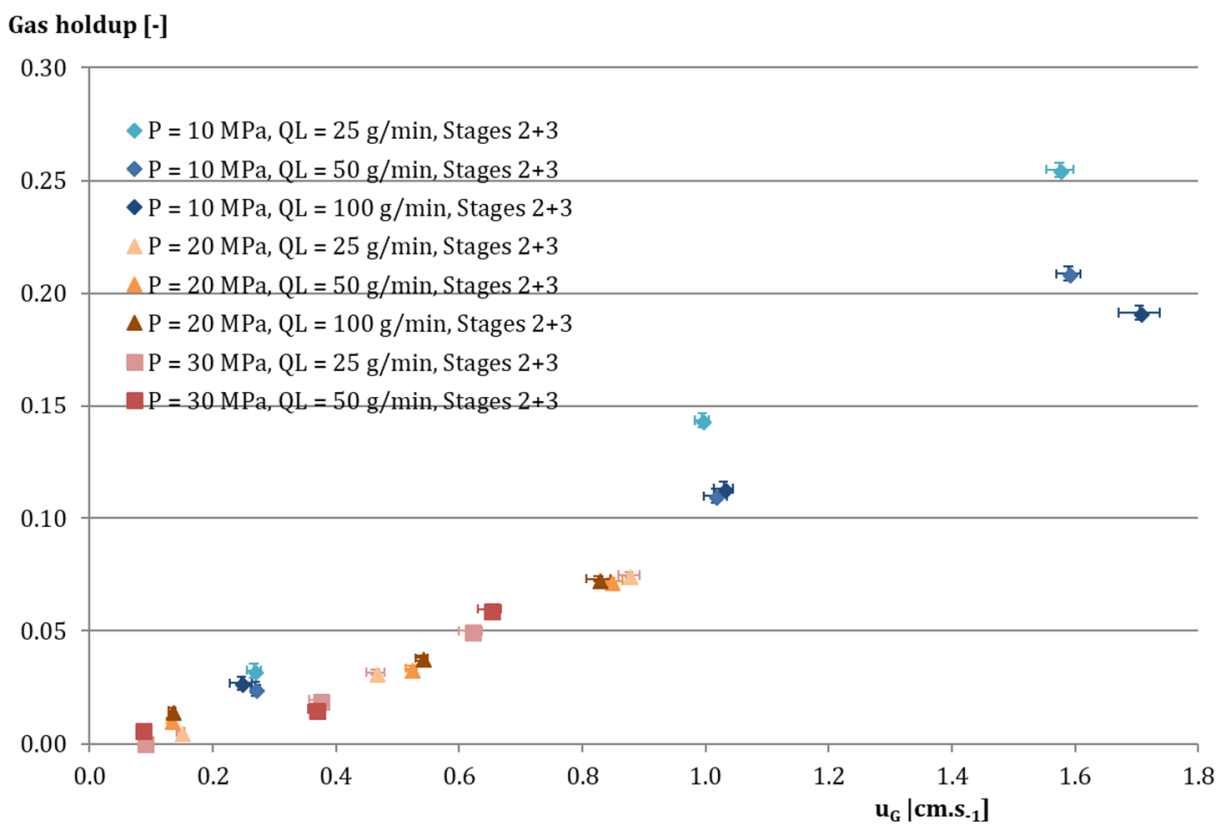

Figure E2: Gas hold up measurements, for water/nitrogen system, at $T=240^{\circ} \mathrm{C}$. Empty symbols: measurements in the $2^{\text {nd }}$ stage. Full symbols: measurements in $2^{\text {nd }}$ and $3^{\text {rd }}$ stages. Symbols with dark outlines: measurements in the $3^{\text {rd }}$ stage. Colour gradients: liquid flow intensity.

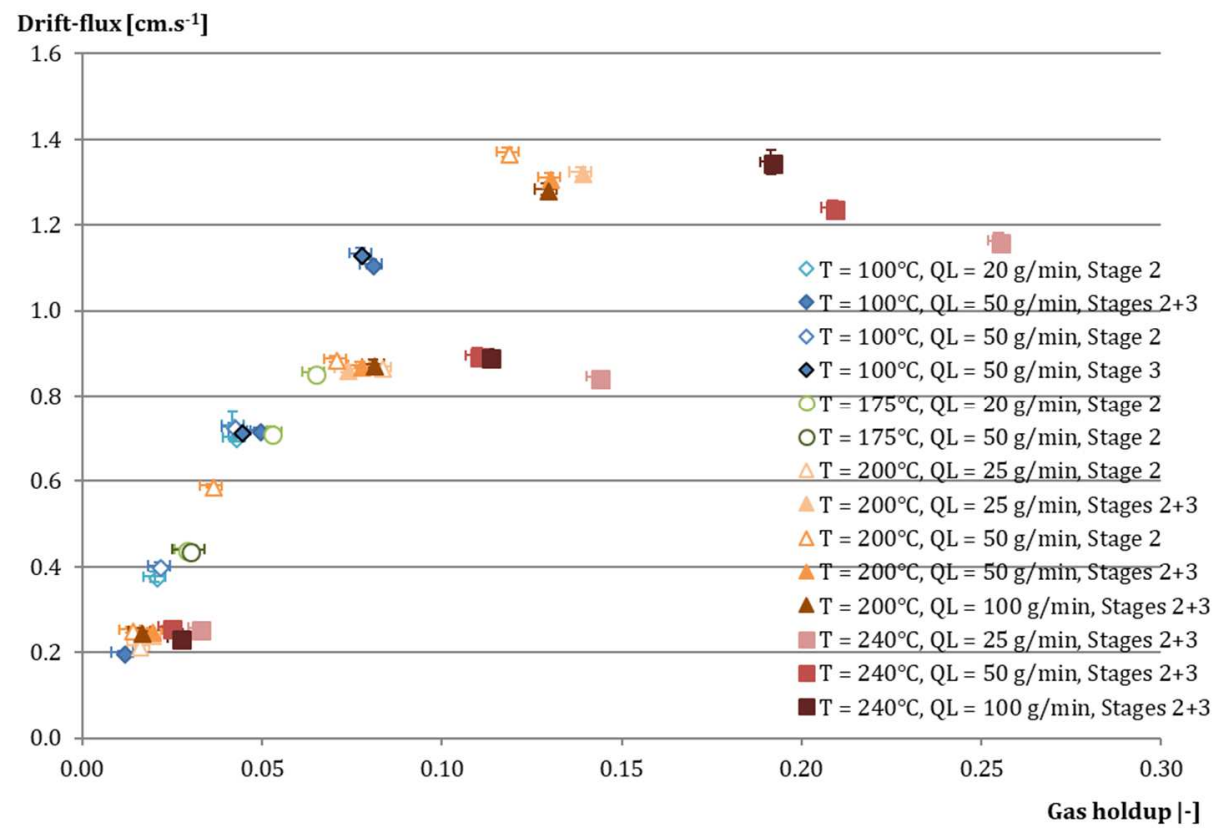

Figure E3: Wallis plot for water/nitrogen system experiments at $P=10 \mathrm{MPa}$. Empty symbols: measurements in the $2^{\text {nd }}$ stage.

Full symbols: measurements in $2^{\text {nd }}$ and $3^{\text {rd }}$ stages. Symbols with dark outlines: measurements in the $3^{\text {rd }}$ stage. Colour gradients: liquid flow intensity. 


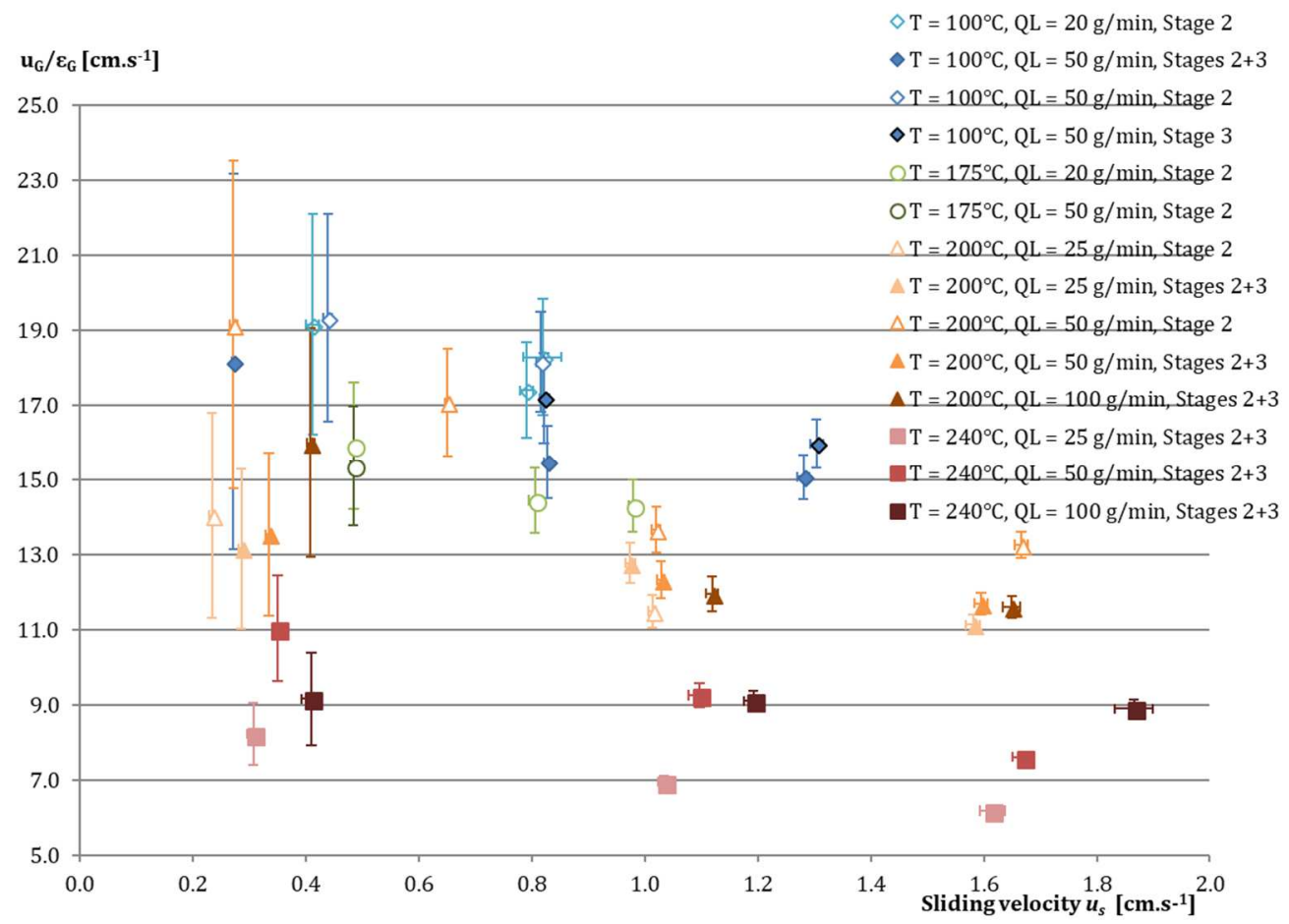

Figure E4: Zuber and Findlay plot, $u_{\mathrm{G}} / \varepsilon_{\mathrm{G}}=\mathrm{f}\left(u_{\mathrm{G}}+u_{\mathrm{L}}\right)$, gas holdup for water/nitrogen at $P=10 \mathrm{MPa}$. Empty symbols: measurements in the $2^{\text {nd }}$ stage. Full symbols: measurements in $2^{\text {nd }}$ and $3^{\text {rd }}$ stages. 


\section{Appendix F Ruzicka model layout}

The layout of the Ruzicka et al. (2001) under saturated conditions is shown in Figure F1.

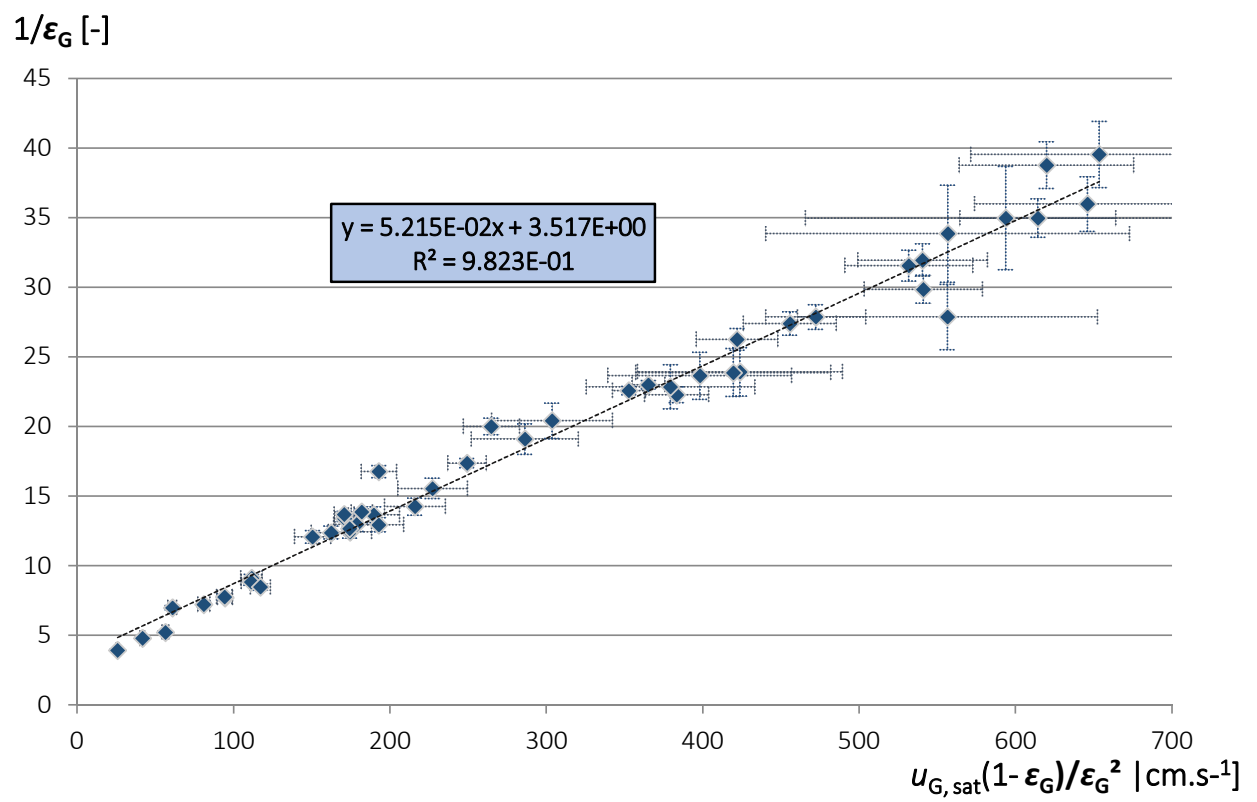

Figure F1: Verification of the Ruzicka model in saturated conditions. Experiments for the system water/nitrogen for $u_{G}$, sat $>$ $0.5 \mathrm{~cm} \cdot \mathrm{s}^{-1}$

The layout of the Ruzicka et al. (2001) under saturated conditions, with distinction of points depending on the ratio $\mathrm{U}_{\mathrm{G} \text {, sat }} / \mathrm{U}_{\mathrm{L} \text {, sat, }}$ is shown in Figure $A 11$. The effect of the $\mathrm{U}_{\mathrm{G} \text {, sat }} / \mathrm{U}_{\mathrm{L} \text {, sat }}$ ratio is observed for values higher than 27. 


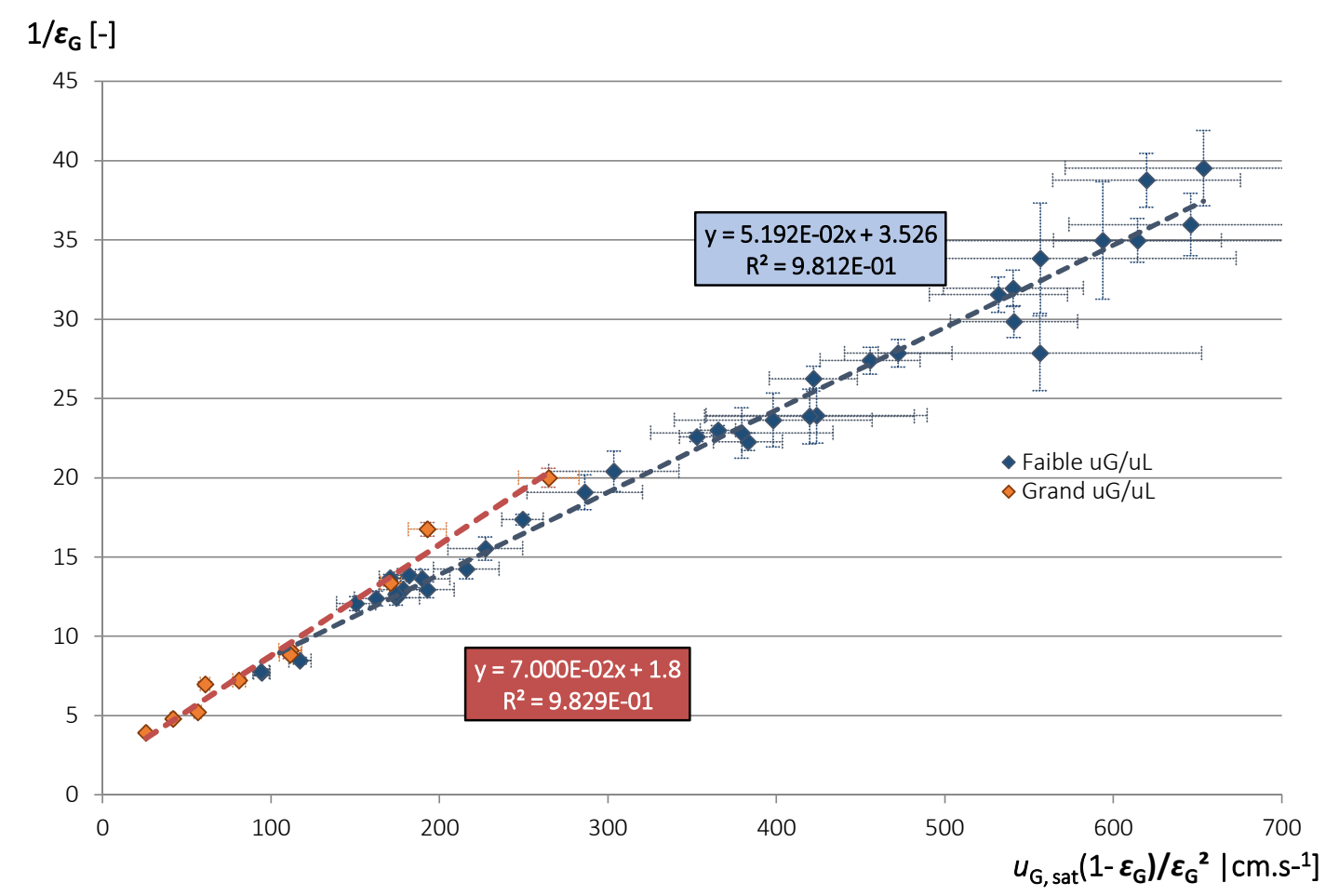

Figure F2: Validation of Ruzicka model in saturated conditions. Experiments in the system water/nitrogen for $u_{G}$, sat $>0.5$ $\mathrm{cm} \cdot \mathrm{s}^{-1}$.

\section{Appendix References}

Friedel, L., 1979. Improved friction pressure drop correlations for horizontal and vertical two-phase pipe flow, European two-phase flow group meeting, Ispra, Italy, paper E2.

Himmelblau, D.M., 1960. Solubilities of inert gases in water. $0^{\circ} \mathrm{C}$. to near the critical point of water, J. Chem. Eng. Data 5, 10-15.

NIST National Institute of Standards and Technology, http://webbook.nist.gov/chemistry/.

Tang, C., Heindel, T.J., 2005. Estimation of gas holdup via pressure difference measurements in a cocurrent bubble column, International Journal of Multiphase Flow 32, 850-863. 
Whalley, P.B., Hewitt, G.F., 1978. The correlation of liquid enyrainment fraction and entrainment rate in annular two-phase low. Rept. AERE-R9187, UKAEA, Harwell. 